\title{
Lens-regulated retinoic acid signalling controls expansion of the developing eye
}

\author{
Jonathan N. Smith ${ }^{1, *}$, Heather M. Walker ${ }^{1, *}$, Hannah Thompson ${ }^{2}$, J. Martin Collinson ${ }^{1}$, Neil Vargesson ${ }^{1}$ and \\ Lynda Erskine ${ }^{1, \pm}$
}

\begin{abstract}
Absence of the developing lens results in severe eye defects, including substantial reductions in eye size. How the lens controls eye expansion and the underlying signalling pathways are very poorly defined. We identified $R D H 10$, a gene crucial for retinoic acid synthesis during embryogenesis, as a key factor downregulated in the peripheral retina (presumptive ciliary body region) of lens-removed embryonic chicken eyes prior to overt reductions in eye size. This is associated with a significant decrease in retinoic acid synthesis by lens-removed eyes. Restoring retinoic acid signalling in lens-removed eyes by implanting beads soaked in retinoic acid or retinal, but not vitamin A, rescued eye size. Conversely, blocking retinoic acid synthesis decreased eye size in lens-containing eyes. Production of collagen II and collagen IX, which are major vitreal proteins, is also regulated by the lens and retinoic acid signalling. These data mechanistically link the known roles of both the lens and retinoic acid in normal eye development, and support a model whereby retinoic acid production by the peripheral retina acts downstream of the lens to support vitreous production and eye expansion.
\end{abstract}

KEY WORDS: Ciliary body, Vitreous, Collagen II, Collagen IX, RDH10, Vitamin A

\section{INTRODUCTION}

It has long been established that the lens is a crucial signalling centre controlling normal expansion and development of the eye (Coulombre and Coulombre, 1964). Any perturbation that affects the development or presence of the lens has a profound effect on eye development in all vertebrate species studied to date. This includes the rare human condition of aphakia (Johnson and Cheng, 1997), physical lens removal in chicken embryos (Beebe and Coats, 2000; Coulombre and Coulombre, 1964; Genis-Galvez et al., 1967; Zinn, 1970), toxininduced target lens ablation in mouse embryos (Breitman et al., 1989, 1987), genetic mutations affecting mouse lens development, such as Pitx $3^{-/-}$(Semina et al., 2000), Foxe $3^{-/-}$(Blixt et al., 2000) or Pax6 ${ }^{+/-}$ (Collinson et al., 2001), and evolution-driven lens loss in species of cave fish (Yamamoto and Jeffery, 2000). In the absence of a normal lens, the eye fails to expand [resulting in microphthalmia (small eyes)], the neural retina becomes highly folded within the vitreal cavity and the anterior segment of the eye develops abnormally. Replacing the

${ }^{1}$ School of Medicine, Medical Sciences and Nutrition, Institute of Medical Sciences, University of Aberdeen, Aberdeen AB25 2ZD, UK. ${ }^{2}$ Department of Craniofacial Development and Stem Cell Biology, Kings College, London WC2R 2LS, UK.

${ }^{\star}$ These authors contributed equally to this work

${ }^{\ddagger}$ Author for correspondence (I.erskine@abdn.ac.uk)

(D) H.M.W., 0000-0003-0805-6220; H.T., 0000-0002-7146-4254; J.M.C., 00000002-8111-475X; N.V., 0000-0001-8027-114X; L.E., 0000-0001-6538-9406

Received 28 April 2018; Accepted 14 September 2018 lens with a cellulose bead or a lens that has been killed by boiling does not support normal eye development, demonstrating that the role of the lens is not simply mechanical (Beebe and Coats, 2000; Coulombre and Coulombre, 1964). However, despite the highly conserved role of the lens in regulating eye expansion, the underlying mechanisms are very poorly understood.

Based on classical experiments in the 1950s/1960s, it has been proposed that the lens controls expansion of the eye through regulating production of the vitreous: the gel-like relatively acellular substance that fills the posterior chamber of the eye (Coulombre, 1956; Coulombre and Coulombre, 1964). Vitreous accumulation is thought to drive expansion of the eye akin to air producing inflation of a balloon. Consistent with this idea, the vitreous fails to accumulate in lens-removed chicken eyes (Coulombre and Coulombre, 1964), and developing chicken eyes in which the vitreous has been drained display a similar phenotype to lensremoved eyes (Coulombre, 1956). Altering the composition of the vitreous through enzyme-mediated digestion of vitreal proteins or injection of specific glycosaminoglycans also affects chicken eye size (Halfter, 2008; Halfter et al., 2006). Assembly of the vitreous occurs embryonically (Halfter et al., 2005). However, the role of the lens in controlling production of the vitreous is little understood. The major source of vitreal proteins is the ciliary body, not the lens (Bishop et al., 2002; Dhawan and Beebe, 1994; Halfter et al., 2005; Linsenmayer et al., 1990). The ciliary body develops at the periphery of the optic cup between the iris and neural retina, and short-range signals from the lens induce expression of ciliary body markers in cultured mouse neural retina (Thut et al., 2001). This raises the possibility that the lens acts indirectly to control eye expansion through regulating development and function of the ciliary body. However, this idea has not been investigated previously.

The eye is extremely sensitive to levels of vitamin A (Warkany and Schraffenberger, 1946; Wilson et al., 1953), and vitamin A deficiency during development results in a range of severe ocular defects, including anophthalmia, microphthalmia, coloboma, failure of vitreous development, abnormal development of the eye lids, conjunctival sacs, anterior chamber, iris and ciliary body, and disorganisation and folding of the retina (Maden et al., 2007; Warkany and Schraffenberger, 1946; Wilson et al., 1953). Vitamin $\mathrm{A}$ is oxidised to its active metabolite retinoic acid in a two-step process: retinal dehydrogenases of the alcohol dehydrogenase and short chain dehydrogenase/reductase families convert vitamin A (retinol) to retinal (retinaldehyde) and retinaldehyde dehydrogenases subsequently convert retinal to retinoic acid (Duester et al., 2003; Shannon et al., 2017).

Here, we show that the lens plays an essential role in patterning the presumptive ciliary body region, including regulating expression of $R D H 10$, a gene that is crucial for the first step in retinoic acid synthesis (Sandell et al., 2007). Retinoic acid synthesis is decreased in lens-removed chicken eyes and restoring retinoic 
acid signalling in lens-removed eyes is sufficient to rescue eye size. Furthermore, both the lens and retinoic acid regulate the synthesis of vitreal proteins by the peripheral retina. These data advance substantially our understanding of the mechanisms by which the lens controls expansion of the eye and provide a functional link between two classical paradigms known to be essential for normal eye development: lens-mediated and retinoic acid signalling.

\section{RESULTS}

\section{The lens regulates patterning of the peripheral retina} (presumptive ciliary body region)

To test the idea that the lens controls expansion of the eye through regulating patterning of the peripheral optic cup, we used in situ hybridisation to analyse expression of several genes implicated in regulating ciliary body development $[B M P 7, O T X 1, R D H 10$ and WNT2B (Cho and Cepko, 2006; Kubo and Nakagawa, 2009; Kubo et al., 2003; Martinez-Morales et al., 2001; Zhao et al., 2002)] in control and lens-removed eyes (Fig. 1). Lenses were removed or, as a damage control, removed and replaced immediately from one eye of HH stage 23 [HH23; embryonic day (E) 4] chicken embryos and the heads fixed, sectioned and stained $24 \mathrm{~h}$ later. The contralateral unoperated eye also acted as a control. E4 is the earliest stage at which the lens induces consistent changes in gene expression in the optic cup (Thut et al., 2001).

Removal of the lens resulted in substantial downregulation within the peripheral retina in expression of all genes analysed. In contralateral unoperated eyes, BMP7, OTX1, RDH10 and WNT2B were expressed strongly in the peripheral retina region that gives rise to the ciliary body and iris (Fig. 1C). In contrast, $24 \mathrm{~h}$ following removal of the lens, expression of $B M P 7, O T X 1$, and $R D H 10$ was virtually undetectable in the peripheral retina, whereas $W N T 2 B$ appeared to be expressed at lower levels and restricted to a smaller domain (Fig. 1C). Real-time PCR confirmed significant downregulation of $W N T 2 B$ expression in lens-removed eyes (Fig. 1D). Confirming that the loss of gene expression in lensremoved eyes was not due to damage to the eye, expression of $B M P 7$, $O T X 1, R D H 10$ and $W N T 2 B$ was maintained in eyes in which the lens was removed and replaced immediately (Fig. 1C,D). These findings demonstrate an essential role for the lens in maintaining gene expression within the peripheral retina, and are consistent with the idea that the lens controls expansion of the eye through regulating peripheral retina identity and function. The downregulation in the peripheral retina of $R D H 10$, a gene essential for embryonic retinoic acid synthesis (Sandell et al., 2007), raised the possibility that retinoic acid signalling may be impaired in lens-removed eyes. Because regulation of retinoic acid levels is essential for normal eye development (Maden et al., 2007; Sandell et al., 2007; Warkany and Schraffenberger, 1946; Wilson et al., 1953), subsequent experiments focused on establishing whether RDH10 is a key factor downstream of the lens essential for normal development of the eye.

\section{RDH10 expression is downregulated rapidly in the peripheral retina, but not the retinal pigmented epithelium (RPE), of lens-removed eyes}

$\mathrm{RDH} 10$ is expressed in peripheral, but not more central, retina, as well as in the central RPE (Fig. 2A). Removal of the lens at HH23
A
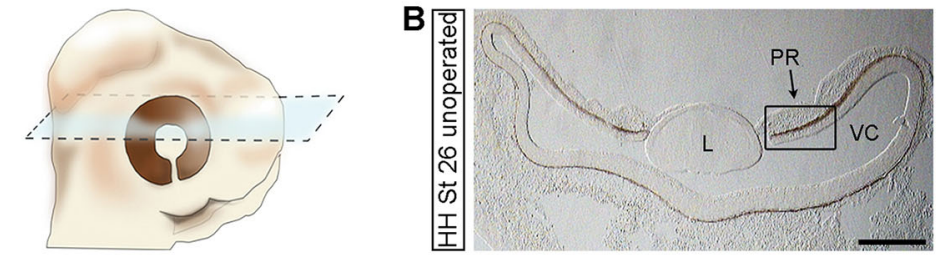

C Unoperated + $24 \mathrm{hrs}$

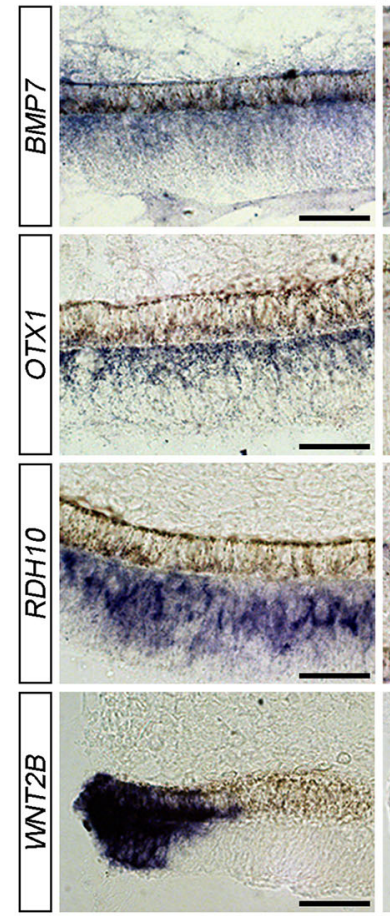

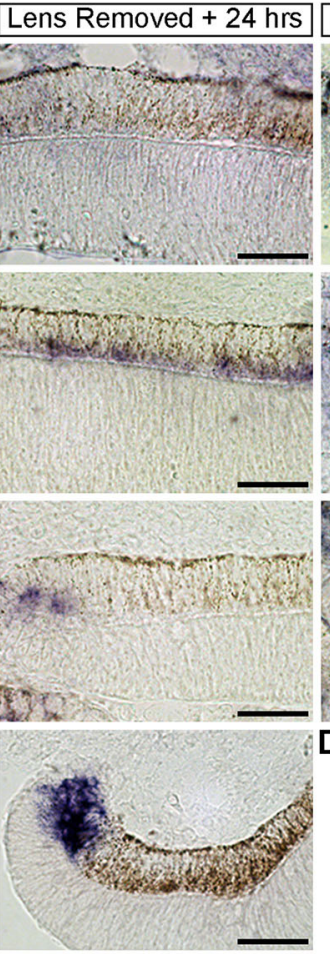

Lens Replaced + 24 hrs

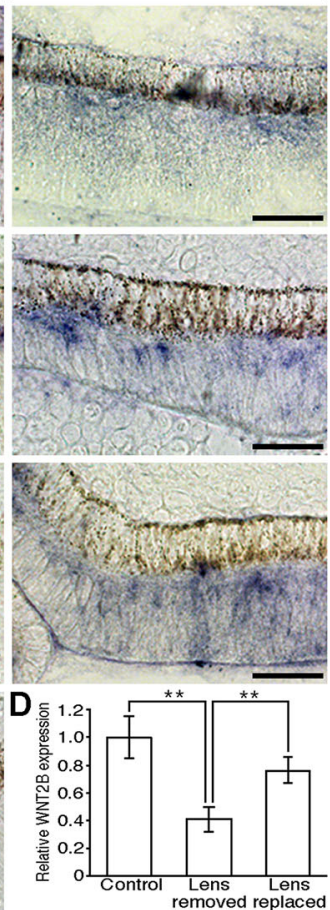

Fig. 1. The lens regulates peripheral retina identity.

(A) Schematic diagram illustrating the sectioning plane. (B) Brightfield image of a section through an unoperated $\mathrm{HH} 26$ retina. Box indicates the region of each retina imaged in $\mathrm{C}$. (C) In situ hybridisation with probes specific for BMP7, OTX1, RDH10 and WNT2B on sections through contralateral unoperated control eyes, eyes in which the lens was removed, or eyes in which the lens was removed and replaced immediately at $\mathrm{HH} 23$, and fixed $24 \mathrm{~h}$ later. (D) Real-time PCR for WNT2B using cDNA prepared from control, unoperated $\mathrm{HH} 26$ eyes or eyes in which the lens was removed or removed and replaced immediately at $\mathrm{HH} 23$ and re-incubated for $24 \mathrm{~h}$. Results are mean ( \pm s.e.m.) of three independent experiments. ${ }^{* *} P<0.01$; one-way ANOVA with Tukey's post-hoc comparison. L, lens; PR, peripheral retina; VC, vitreal cavity. Scale bars: $500 \mu \mathrm{m}$ in B; $50 \mu \mathrm{m}$ in C. 


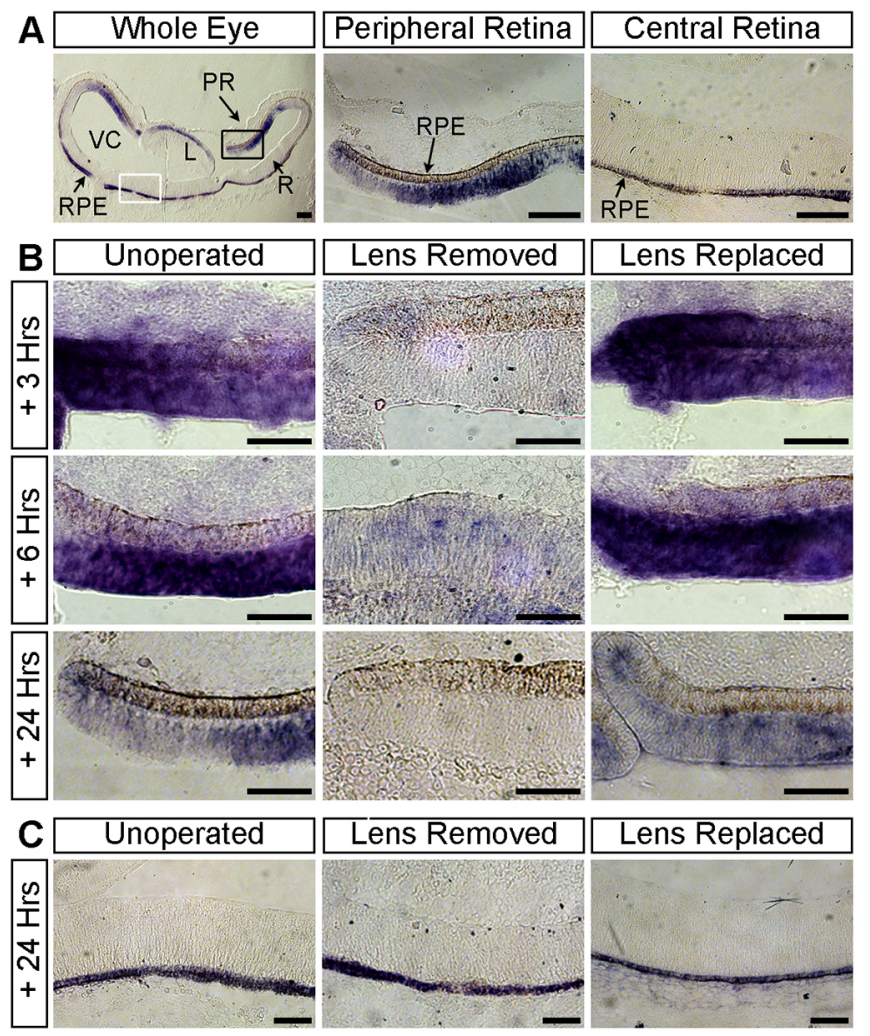

Fig. 2. The lens controls expression of $R D H 10$ in the peripheral retina but not the RPE. (A) Section through a control, unoperated $\mathrm{HH} 26$ eye stained by in situ hybridisation with a probe specific for $R D H 10$. Boxed regions in the peripheral retina (black) and central retina (white) are shown at higher magnification in the right-hand panels. (B,C) $\mathrm{RDH10}$ expression in the peripheral retina $(B)$ and central retina $(C)$ in contralateral unoperated control eyes or in eyes in which the lens was removed or removed and replaced immediately, and fixed 3, 6 or $24 \mathrm{~h}$ later. RPE is towards the top of each panel in the peripheral retina images and towards the bottom in the central retina images. L, lens; $P R$, peripheral retina; $R$, neural retina; $R P E$, retinal pigmented epithelium; VC, vitreal cavity. Scale bars: $100 \mu \mathrm{m}$ in A; $50 \mu \mathrm{m}$ in B,C.

resulted in substantial downregulation of $\mathrm{RDH} 10$ expression in the peripheral retina within $3 \mathrm{~h}$ of lens removal compared with the unoperated contralateral eye or with eyes in which the lens was removed and replaced immediately (Fig. 2B; $n=5 / 5$ ). RDH10 continued to be expressed at reduced levels in the peripheral retina of lens-removed eyes compared with unoperated and lens-replaced eyes for at least $24 \mathrm{~h}$ following lens removal (Figs $1 \mathrm{C}$ and 2B; $6 \mathrm{~h}$, $n=5 / 5 ; 24 \mathrm{~h}, n=6 / 6)$. In contrast, expression in the RPE was not altered obviously (Fig. 2C; Fig. S1A). Attempts to confirm the downregulation of $\mathrm{RDH1O}$ in the peripheral retina of lens-removed eyes using real-time PCR on cDNA prepared from the whole eye proved inconclusive, likely due to the maintained expression of RDH10 in the RPE (Fig. S1). Nevertheless, these findings demonstrate an essential role for the lens in maintaining $\mathrm{RDH} 10$ expression in the peripheral retina but not the RPE.

\section{Downregulation of $R D H 10$ in the peripheral retina precedes significant changes in eye size}

To determine whether downregulation of $\mathrm{RDH} 10$ in lens-removed eyes precedes changes in eye size, lenses were removed or removed and replaced immediately from $\mathrm{HH} 23$ chicken embryos and eye size was determined 3, 6, or $24 \mathrm{~h}$ later (Fig. 3A). Quantification of eye size (mean of the horizontal and vertical diameters; Fig. 3B) revealed no significant difference in eye size 3 or $6 \mathrm{~h}$ following lens removal compared with unoperated or lens-replaced eyes (Fig. 3A,C). By $24 \mathrm{~h}$ following lens removal, eye size was decreased significantly (Fig. 3A,C). These findings demonstrate that downregulation of $\mathrm{RDH} 10$ in lens-removed eyes (Fig. 2B) occurs prior to overt changes in eye size. Removing and immediately replacing the lens had no significant impact on eye size at all time points, confirming that the smaller size of lens-removed eyes is not the result of damage or the healing response (Fig. 3A,C).

Analysis of eye size at later time points following lens removal revealed that the reduction in eye size was permanent, with no evidence of recovery (Fig. 3D,E). From HH23 (E4) to E10 control unoperated and lens-replaced eyes displayed a linear increase in size and by E10 had increased in diameter approximately eightfold compared with E4 (Fig. 3D,E). In contrast, eyes in which the lens was removed at E4 failed to increase in size and by E10 were not significantly different in size from E4 unoperated or lens-replaced eyes (Fig. 3D,E).

\section{The retina continues to expand in lens-removed eyes}

Sections through the eye demonstrated that, whereas overall eye size is severely impaired, the retina continues to grow in the absence of the lens. Lenses were removed or removed and replaced immediately from $\mathrm{HH} 23$ chicken eyes and the heads fixed and sectioned $24 \mathrm{~h}$ later. Both unoperated and lens-replaced eyes had a large vitreal cavity and the neural retina was closely associated with the RPE along its entire length (Fig. 4A). In lens-removed eyes, the vitreal cavity was reduced substantially in size and, in places, the neural retina had become detached from the RPE and folded within the vitreal cavity (Fig. 4A). Quantification demonstrated that retinal cell number increased from $\mathrm{HH} 23$ (E4) to E6 in both control and lens-removed eyes, but that the total number of cells was significantly lower in retinas from E6 lens-removed eyes compared with retinas from control eyes (Fig. S2A,B). These findings demonstrate that the retina continues to grow for at least $48 \mathrm{~h}$ following removal of the lens, but its growth is impaired compared with control eyes. Because during this period lensremoved eyes do not increase significantly in size (Fig. 3D,E), we cannot exclude the possibility that the reduced number of retinal cells in lens-removed eyes results from the restricted space available into which the retina can expand rather than from a direct effect of loss of the lens. Consistent with the idea that the lens is not a key regulator of retinal growth, the number of phosphohistone-H3-positive mitotic cells per $\mathrm{mm}$ of the whole retina or within the peripheral $200 \mu \mathrm{m}$ of the retina was not altered significantly 3, 6 or $24 \mathrm{~h}$ following lens removal (Fig. S2C-E) Because the retina continues to expand in the absence of the lens, disproportionate to other ocular tissues, growth of the retina is unlikely to be a major driving force for eye expansion.

\section{Retinal lamination and patterning are maintained in lens-removed eyes}

To determine whether the loss of peripheral retina identity (Fig. 1C) in lens-removed eyes reflects a general disruption of eye development, we analysed retinal lamination and patterning in sections through eyes in which the lens was removed at $\mathrm{HH} 23$ and fixed 2 (E6; HH28) or 6 (E10; HH35) days later. In HH28 unoperated and lens-replaced eyes, islet-positive retinal ganglion cells and amacrine cells were located at the inner vitreal surface of the retina, whereas phosphohistone $\mathrm{H} 3$-positive mitotic cells were located at the ventricular surface, adjacent to the RPE (Fig. 4B). This was also the case in lens-removed eyes, including in regions 

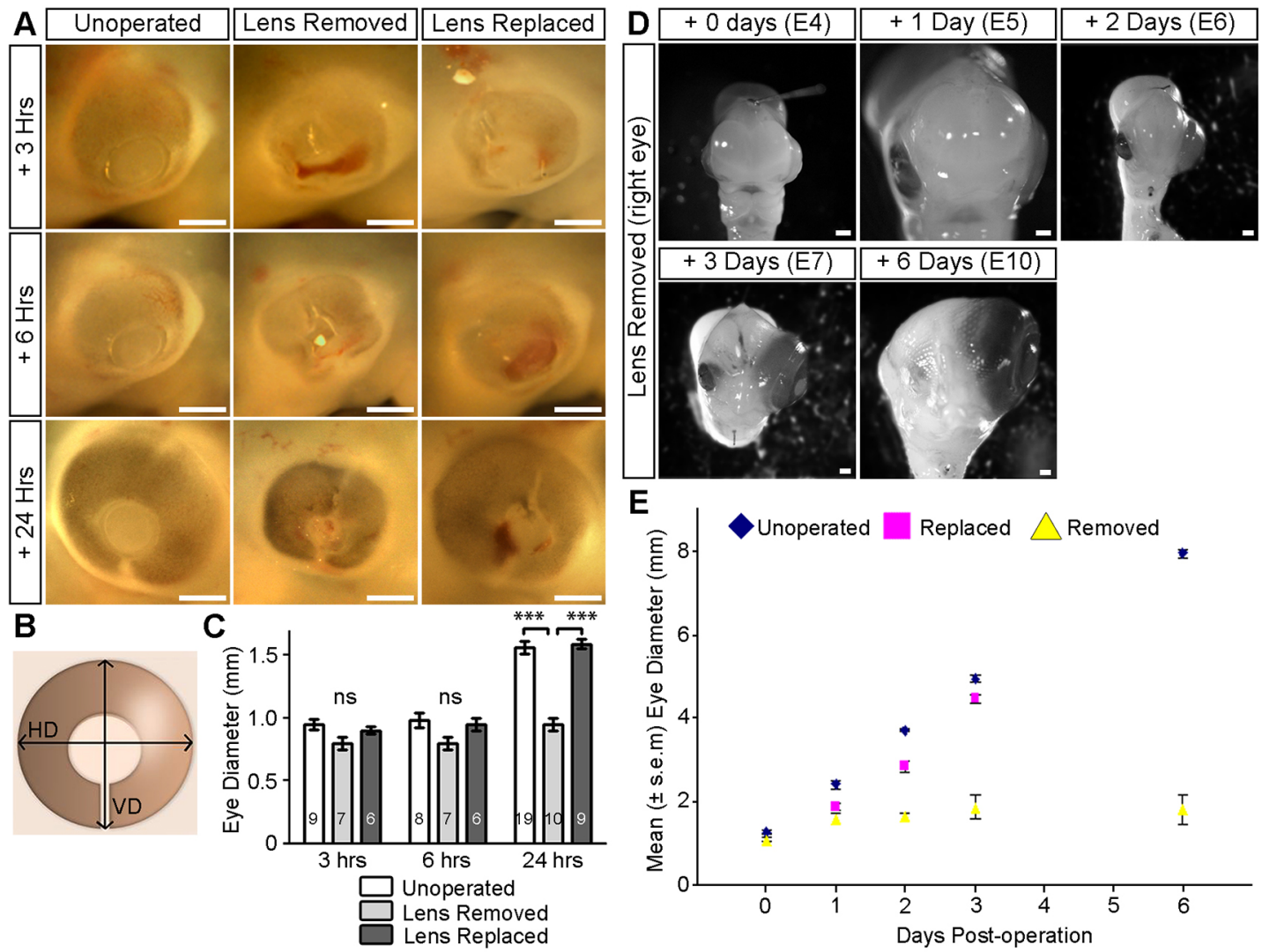

Fig. 3. Overt changes in eye size occur on a slower timescale than downregulation of RDH10. (A) Whole-mount views of contralateral unoperated control eyes, or eyes in which the lens was removed or removed and replaced immediately at $\mathrm{HH} 23$, and fixed after 3, 6 or $24 \mathrm{~h}$ re-incubation. (B) Eye diameter was calculated as the mean of the vertical (VD) and horizontal (HD) diameters. (C) Mean ( \pm s.e.m.) diameter of unoperated, lens-removed and lens-replaced eyes fixed 3 , 6 or $24 \mathrm{~h}$ after operation at $\mathrm{HH} 23$. Numbers on bars indicate numbers analysed for each condition and time point. ns, not significant, ${ }^{* * *} P<0.001$. One-way ANOVA with Tukey's post-hoc comparison. (D) Whole-head images, viewed from the front of chicken embryo heads fixed immediately following removal of the right lens at $\mathrm{HH} 23$ (E4) or 1 (E5; HH26), 2 (E6; HH28), 3 (E7; HH31) or 6 (E10; HH35) days after lens removal. (E) Mean ( \pm s.e.m.) diameter of unoperated, lens-removed and lens-replaced eyes 0 days (immediately following lens removal at $\mathrm{HH} 23$ ) to 6 days post lens removal. Scale bars: $500 \mu \mathrm{m}$ in $\mathrm{A}$; $1 \mathrm{~mm}$ in $\mathrm{D}$.

where the retina had become highly folded (Fig. 4B). By E10, the mature retinal layers are beginning to form. Staining with anti-islet $1 / 2$ or with DAPI demonstrated that these layers developed relatively normally in lens-removed eyes, although the layers appeared thicker and slightly disorganised in regions where the retina was folded (Fig. S3).

Dorsal-ventral patterning also appeared normal in lens-removed eyes. $T B X 5$ is expressed normally in the dorsal retina and $c V A X$ in ventral retina (Fig. 4C). Despite the smaller size of the eye and folding of the retina, the restricted expression of $T B X 5$ to the dorsal retina and $c V A X$ to the ventral retina was maintained in lensremoved eyes (Fig. 4C). We conclude that retinal lamination and patterning is not altered substantially in the absence of the lens.

\section{Expression of RALDH1-RALDH3 is maintained in lens- removed eyes}

Retinoic acid is produced from vitamin A (retinol) in a two-step process: retinol dehydrogenases, such as RDH10, oxidise vitamin A to produce retinal (retinaldehyde), which is subsequently oxidised by retinal dehydrogenases (RALDH1-RALDH3) to produce retinoic acid (Fig. 5A). Using in situ hybridisation on sections through heads in which the lens was removed at $\mathrm{HH} 23$ and fixed $24 \mathrm{~h}$ later, we found that expression of RALDH1-RALDH3 (ALDH1A1-ALDH1A3) is maintained in lens-removed eyes, including in the peripheral retina (Fig. 5B). In both contralateral unoperated eyes and lens-removed eyes, $R A L D H 1$ was expressed strongly in dorsal retina and $R A L D H 3$ in ventral retina (Fig. 5B). In control eyes, $\mathrm{RALDH} 2$ was expressed in two distinct domains flanking the lens. $\mathrm{RALDH} 2$ expression was maintained following lens removal, but the $R A L D H 2$-positive domains were brought together (Fig. 5B). We conclude that, in contrast to RDH10, maintenance of ocular RALDH1-RALDH3 expression is not dependent on signals from the lens.

\section{Retinoic acid synthesis is reduced in lens-removed eyes}

To investigate whether retinoic acid synthesis is impaired in lensremoved eyes, we used retinoic acid-reporter cells (Sil-15 cells; Wagner et al., 1992) to quantify retinoic acid production by unoperated, lens-removed and lens-replaced eyes (Fig. 6A). These cells have been stably transfected with $\beta$-galactosidase under the control of a retinoic acid response element (RARE) and, consequently, respond to retinoic acid with proportional increases in $\beta$-galactosidase activity (Fig. 6B).

Lenses were removed or removed and replaced immediately from $\mathrm{HH} 23$ embryos and the embryos re-incubated for $24 \mathrm{~h}$. The operated and contralateral control eyes were dissected out and cultured overnight in serum-free medium. The conditioned medium was added to a confluent layer of the reporter cells, incubated for $24 \mathrm{~h}$ and the cells assayed for $\beta$-galactosidase activity (Fig. 6A). In each experiment, cells were exposed in parallel to conditioned medium from cultures of unoperated, lens-removed and lens-replaced eyes, as well as known concentrations of retinoic acid (Fig. 6B-E). 

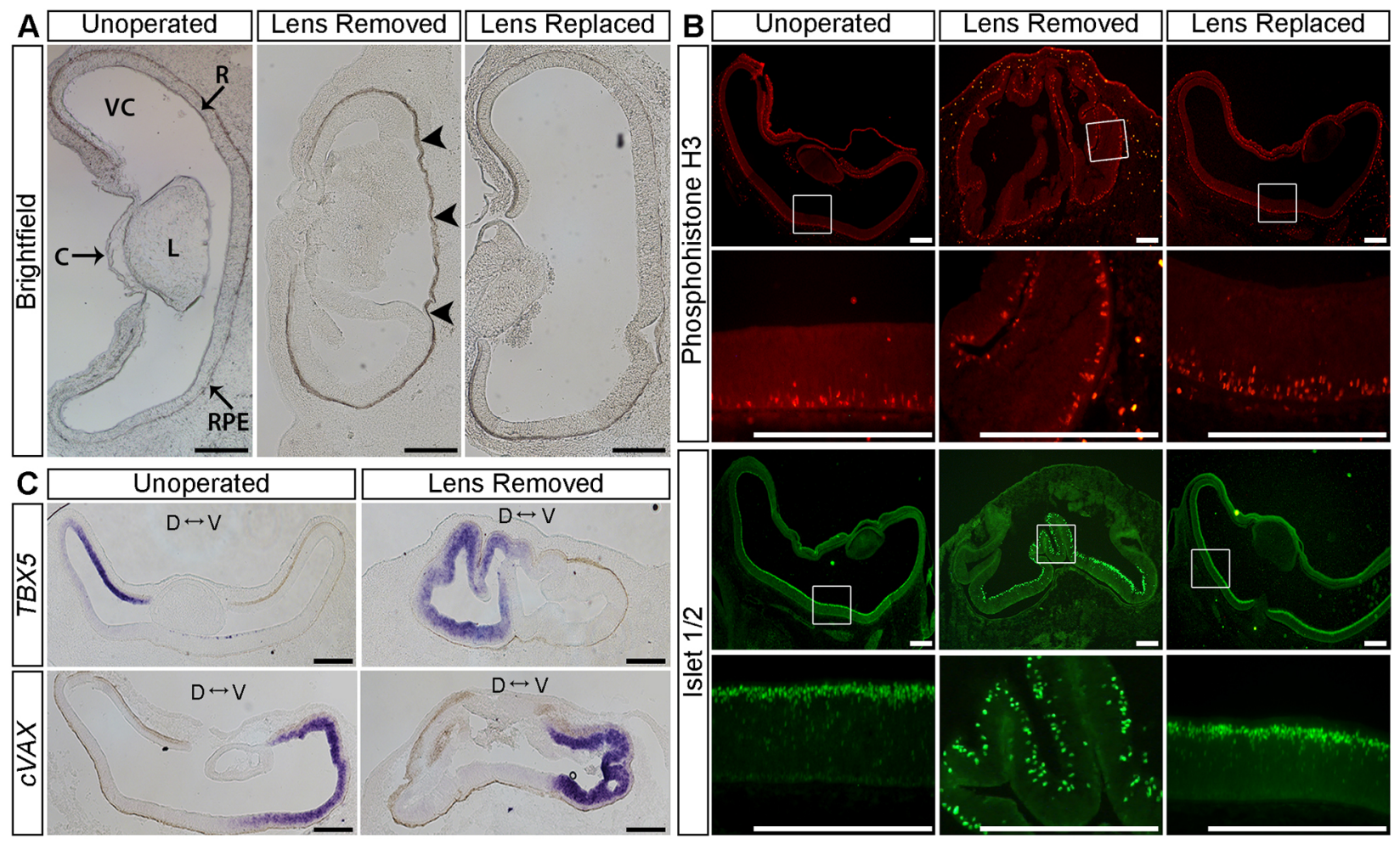

Fig. 4. Retinal lamination and patterning is normal in lens-removed eyes. (A) Sections through contralateral unoperated, lens-removed and lens-replaced eyes fixed $24 \mathrm{~h}$ after surgery at $\mathrm{HH} 23$. Arrowheads indicate detachment of the retina from the RPE and folding into the vitreal cavity in the absence of the lens. (B) Sections through unoperated, lens-removed and lens-replaced eyes fixed $48 \mathrm{~h}$ after surgery at $\mathrm{HH} 23$ and stained using antibodies against phosphohistone $\mathrm{H} 3$ to label mitotic cells (red) or islet 1/islet 2 to label retinal ganglion and amacrine cells (green). Boxed regions are shown at higher magnification in the lower panels. (C) Sections through unoperated and lens-removed eyes fixed $24 \mathrm{~h}$ after surgery at $\mathrm{HH} 23$ stained by in situ hybridisation using probes specific for TBX5 or $\mathrm{cVAX}$. C, cornea; D, dorsal; L, lens; R, neural retina; RPE, retinal pigmented epithelium; V, ventral; VC, vitreal cavity. Scale bars: $250 \mu \mathrm{m}$.

Staining for $\beta$-galactosidase activity revealed a significant reduction in retinoic acid synthesis by the lens-removed eyes (Fig. 6D,E). In cultures of reporter cells exposed to medium conditioned by lens-removed eyes, many fewer $\beta$-galactosidasepositive cells were detected compared with cultures incubated with medium conditioned by unoperated or lens-replaced eyes (Fig. 6D). Accordingly, quantification of retinoic acid concentration by measuring the absorbance of the cells and comparing this with the standard curve, demonstrated that the retinoic acid concentration in medium conditioned by lens-removed eyes was significantly lower compared with medium conditioned by unoperated or lensreplaced eyes (Fig. 6E). These findings demonstrate that ocular production of retinoic acid is decreased in the absence of the lens.

\section{Exogenous retinoic acid and retinal, but not vitamin $A$, rescue eye size in the absence of the lens}

Next, we asked whether adding exogenous retinoic acid could rescue expansion of lens-removed eyes. The lens was removed from one eye of HH23 chicken embryos and replaced with an AG1-X2 bead (BioRad) soaked in all-trans-retinoic acid $(0.1 \mathrm{mg} / \mathrm{ml}$ in DMSO) or vehicle alone (DMSO). These beads continuously release retinoic acid for at least $24 \mathrm{~h}$, creating a local tissue gradient of retinoic acid in the picomolar to nanomolar range (Tickle et al., 1985). Embryos were re-incubated for $24 \mathrm{~h}$ and eye size measured in comparison with the unoperated contralateral eye. Beads soaked in retinoic acid, but not control (DMSO) beads, rescued eye size in the absence of the lens (Fig. 7A,D). The morphology of the eye was also restored (Fig. 7B). Similar to lens-removed eyes, eyes in which the lens was replaced with a bead soaked in DMSO had a small vitreal cavity, the retina and RPE were detached in places, and the retina was folded within the vitreal cavity. In contrast, the morphology of eyes in which the lens was replaced with a bead soaked in retinoic acid was indistinguishable from unoperated eyes, with a large vitreal cavity, and the neural retina unfolded and in contact with the RPE along its entire length (Fig. 7B). Consistent with our finding that expression of RDH10 (oxidises vitamin A to retinal) but not that of RALDH1-RALDH3 (oxidise retinal to retinoic acid) is decreased substantially in lens-removed eyes, beads soaked in retinal $(1 \mathrm{mg} / \mathrm{ml})$ also rescued eye size and morphology in the absence of the lens (Fig. 7A,B,D). Conversely, beads soaked in vitamin A (retinol; $1 \mathrm{mg} / \mathrm{ml}$ ), were unable to rescue eye size or morphology in lens-removed eyes (Fig. 7A,B,D), consistent with the idea that RDH10-mediated conversion of vitamin A to retinal is impaired in lens-removed eyes. Importantly, implanting beads soaked in retinoic acid or retinal in wounded, lens-containing eyes had no significant effect on eye size (Fig. 7C,E). This demonstrates that rescue of eye size in lens-removed eyes by retinoic acid or retinal is unlikely to be the result of a non-specific effect on the wounding response or cell proliferation. We conclude that increasing retinoic acid levels in lens-removed eyes is sufficient to rescue eye size and restore normal morphology.

\section{Inhibiting retinoic acid synthesis decreases eye size}

To test whether retinoic acid is essential for normal expansion of the eye, small pieces of gelatine sponge soaked in DMSO or disulfiram $(1,10$ or $25 \mathrm{mg} / \mathrm{ml}$ in DMSO) were applied on top of one eye of HH23 embryos and eye size determined $24 \mathrm{~h}$ later. Disulfiram inhibits aldehyde dehydrogenases and is a potent inhibitor of 


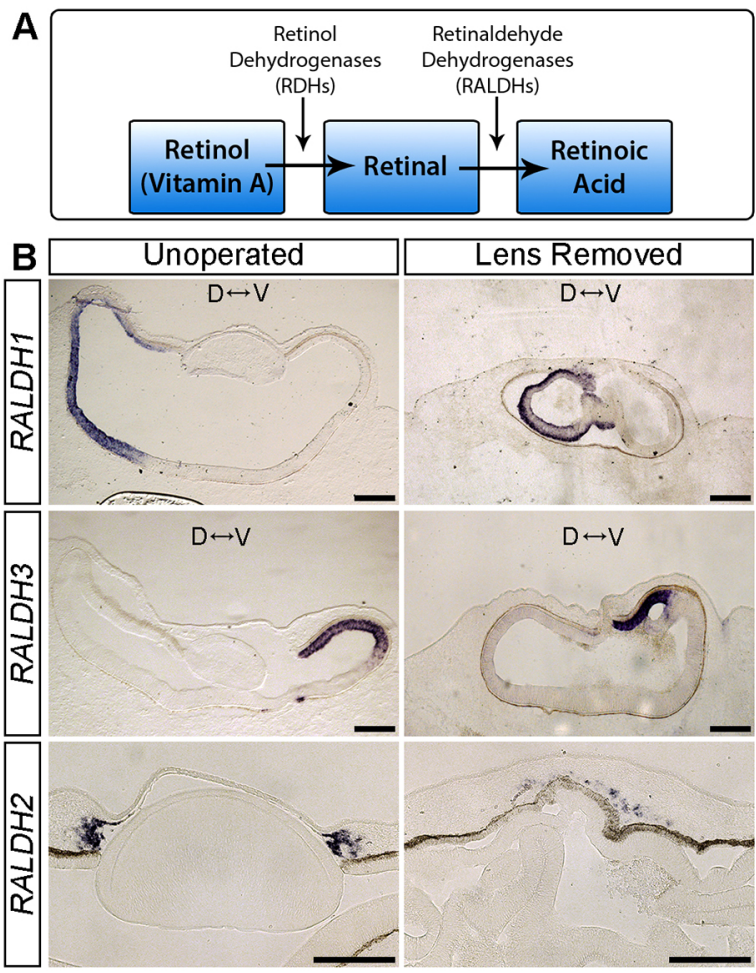

Fig. 5. Expression of RALDH1-RALDH3 is maintained in lens-removed eyes. (A) Schematic showing the retinoic acid synthesis pathway. (B) In situ hybridisation with probes specific for RALDH1, RALDH2 and RALDH3 on sections through contralateral unoperated eyes and eyes in which the lens was removed at $\mathrm{HH} 23$ and fixed $24 \mathrm{~h}$ later. D, dorsal; V, ventral. Scale bars: $250 \mu \mathrm{m}$.

retinoic acid synthesis in developing chicken embryos (Vermot and Pourquié, 2005). In agreement with the idea that retinoic acid is essential for generating normal eye size, application of sponges soaked with disulfiram, but not vehicle (DMSO) alone, induced a significant decrease in eye size in a concentration-dependent manner (Fig. 8A,C). However, sectioning of the eye revealed differences in the morphology of the small eyes resulting from disulfiram treatment compared with lens-removed eyes (compare Figs $8 \mathrm{~B}$ and $4 \mathrm{~A}$ ). Whereas in lens-removed eyes the retina grew disproportionate to other eye tissues and tended to become folded within the vitreal cavity (Figs 4, 5B, 7B, Fig. S1A), in disulfiramtreated eyes retinal folding was not observed and growth of the retina appeared proportionate to overall eye size (Fig. 8B). A possible explanation for this difference is that $R D H 10$, and consequently retinoic acid synthesis, is maintained in the RPE of lens-removed eyes, (Fig. 2B,C, Fig. S1A), whereas disulfiram likely reduces retinoic acid synthesis in all ocular tissue.

\section{Localisation of collagens, but not tenascin $\mathrm{C}$, to the peripheral retina is regulated by the lens and retinoic acid signalling}

To test the idea that the lens regulates eye size indirectly through controlling assembly of the vitreous, we analysed the ocular localisation of three major vitreal proteins: tenascin $\mathrm{C}$, collagen II and collagen IX (Bishop et al., 2002; Halfter et al., 2005) (Fig. 9A). Tenascin $\mathrm{C}$ and collagen IX are produced almost exclusively by the presumptive ciliary body region, whereas collagen II is produced both by the ciliary body and, early in development, by the neural retina (Bishop et al., 2002; Dhawan and Beebe, 1994; Halfter et al., 2005, 2008; Linsenmayer et al., 1990).
Following removal of the lens at $\mathrm{HH} 23$, localisation of tenascin $\mathrm{C}$ to the presumptive ciliary body region was maintained 24 and $48 \mathrm{~h}$ later (Fig. 9B,C), demonstrating that the ciliary body retains some aspects of its identity in lens-removed eyes. In contrast, within $3 \mathrm{~h}$ of lens removal, collagen II immunolocalisation was decreased substantially (Fig. 9D,E). Collagen IX immunolocalisation to the presumptive ciliary body also was decreased in lens-removed eyes, but on a slower timescale than collagen II. At 3 and $6 \mathrm{~h}$ following lens removal, collagen IX immunolocalisation to the presumptive ciliary body was indistinguishable from contralateral, unoperated eyes (Fig. 9F). However, $24 \mathrm{~h}$ after lens removal at HH23, collagen IX immunolocalisation was reduced substantially in lens-removed eyes (Fig. 9G).

Next, we asked whether addition of exogenous retinoic acid or retinal could rescue collagen synthesis in lens-removed eyes. For these experiments, we focused on collagen IX because this protein is produced almost exclusively by the presumptive ciliary body region. Similar to lens-removed eyes, replacement of the lens at $\mathrm{HH} 23$ with a bead soaked in DMSO (vehicle control) resulted in a substantial reduction in collagen IX immunolocalisation to the presumptive ciliary body region $24 \mathrm{~h}$ later (Fig. 10A). In contrast, beads soaked in either retinoic acid $(0.1 \mathrm{mg} / \mathrm{ml})$ or retinal $(1 \mathrm{mg} / \mathrm{ml})$ abrogated the reduction in collagen IX immunostaining seen in lensremoved eyes (Fig. 10A).

Collagen IX is composed of three chains encoded by different genes: COL9A1, COL9A2 and COL9A3. To investigate whether the loss of collagen IX immunolocalisation to the peripheral retina of lens-removed eyes results from defective deposition of the protein or downregulation of gene expression, we analysed expression of COL9A1 and COL9A3 in control and lens-removed eyes. We were unable to generate a probe for COL9A2. Lenses were removed from HH23 chicken eyes and the eyes fixed and stained $24 \mathrm{~h}$ later. Compared to the contralateral unoperated eye and eyes in which the lens was removed and replaced immediately, expression of both COL9A1 and COL9A3 was decreased substantially in the peripheral retina of lensremoved eyes (Fig. 10B). Implanting a bead soaked with retinoic acid $(0.1 \mathrm{mg} / \mathrm{ml})$ rescued $C O L 9 A 1$ and $C O L 9 A 3$ expression in lens-removed eyes (Fig. 10B). Expression of TNC also was downregulated in lens-removed eyes, and this loss of expression was abrogated by retinoic acid (Fig. 10B). The maintained localisation of tenascin $\mathrm{C}$ protein to the peripheral retina of lensless eyes (Fig. 9B,C) therefore likely reflects decreased secretion from the peripheral retina and/or increased protein stability compared with collagen IX. Taken as a whole, these findings demonstrate that production of vitreal components is regulated both by the lens and retinoic acid signalling.

\section{DISCUSSION}

Although it has been known for over 50 years that the lens is essential for normal expansion and development of the eye (Coulombre and Coulombre, 1964), the underlying mechanisms have proven elusive. Our findings support a model whereby the lens acts indirectly to control expansion of the eye through regulating patterning of the peripheral optic cup, including maintenance of RDH10 expression, a gene essential for the first step in embryonic retinoic acid synthesis. In turn, RDH10 is essential for ocular retinoic acid synthesis, which regulates both vitreal collagen production and expansion of the eye (Fig. 10C). These findings provide an unexpected link between two classical signalling paradigms that are important for eye development: lens-mediated and retinoic acid signalling. 

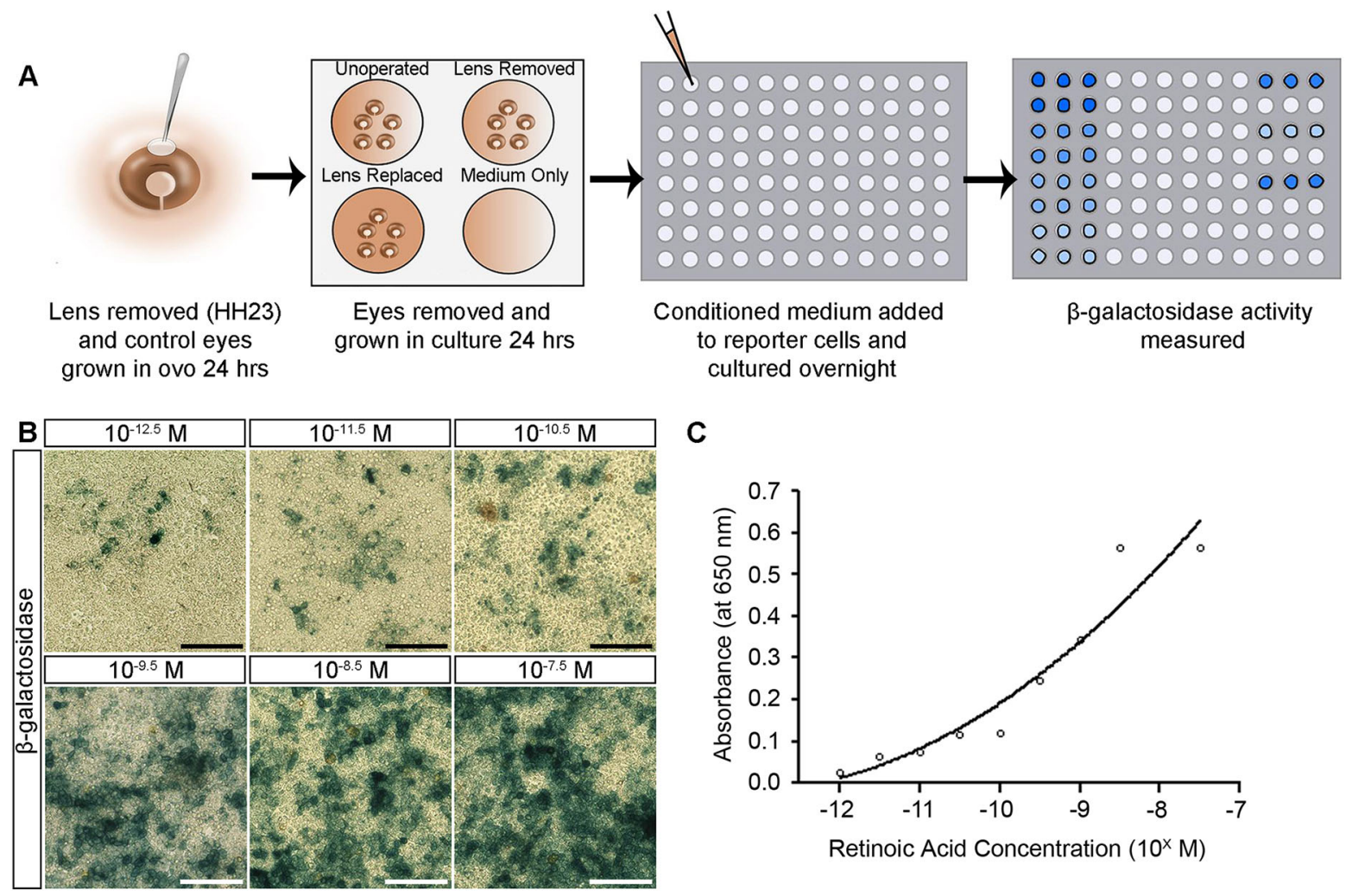

C
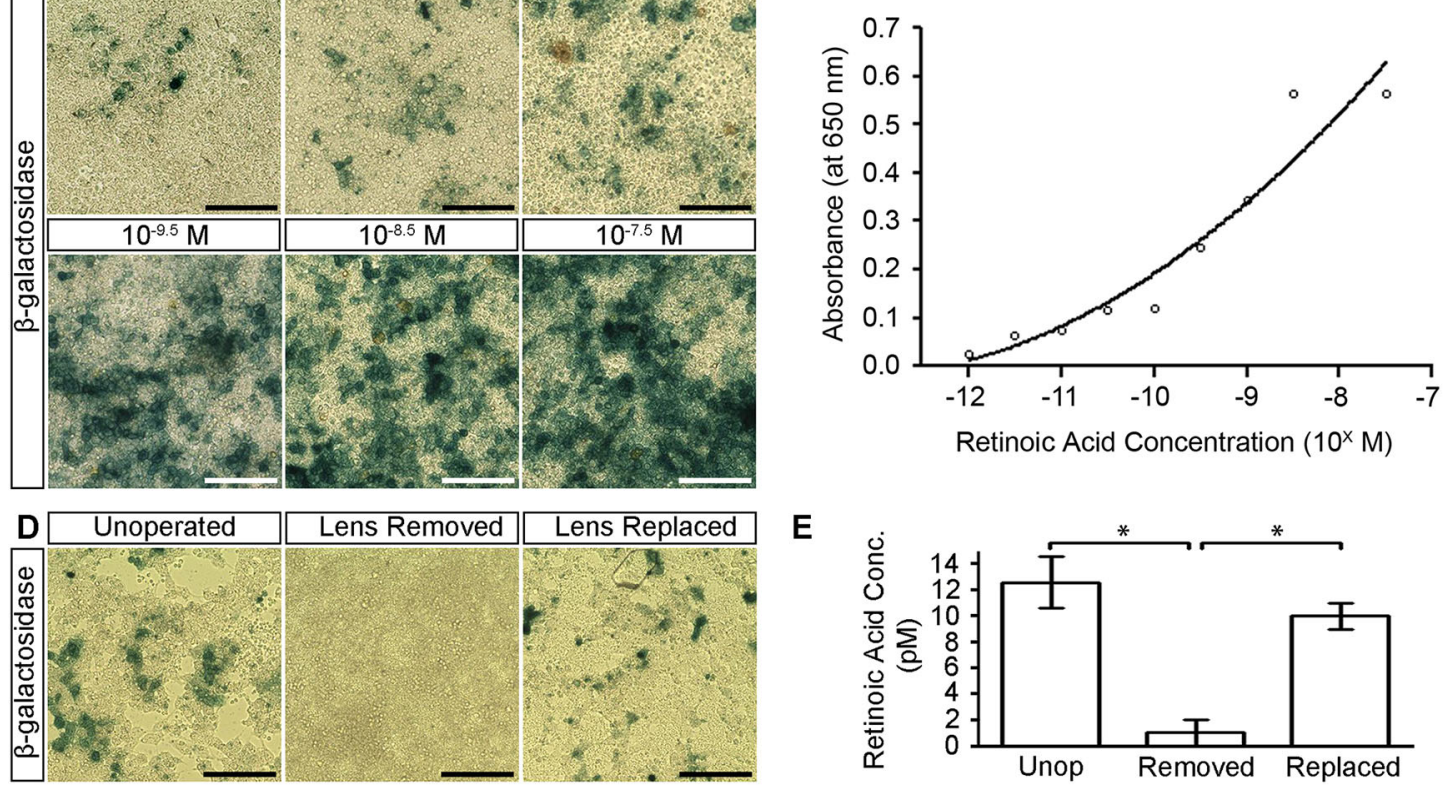

Fig. 6. Retinoic acid synthesis is reduced in lens-removed eyes. (A) Schematic diagram of the method used to quantify retinoic acid synthesis. Lenses were removed, or removed and replaced immediately, from HH23 eyes and the eggs re-incubated for $24 \mathrm{~h}$. The eyes were removed and cultured for $24 \mathrm{~h}$, five per well in four-well plates containing $500 \mu \mathrm{l}$ serum-free medium. The culture medium was transferred to 96 -well plates containing Sil-15 retinoic acid-responsive reporter cells, cultured overnight and $\beta$-galactosidase activity quantified. For each experiment, cells also were exposed to different concentrations of retinoic acid. (B) $\beta$-Galactosidase activity in Sil-15 reporter cells exposed to medium containing retinoic acid concentrations from $10^{-12.5} \mathrm{M}$ to $10^{-7.5} \mathrm{M}$. Increasing the concentration of retinoic acid in the medium results in a proportional increase in $\beta$-galactosidase activity in the reporter cells. (C) Absorbance reading in cells increases as retinoic acid concentration increases. (D) $\beta$-Galactosidase activity in Sil-15 cells exposed to medium from cultured unoperated, lens-removed and lens-replaced eyes. (E) Mean ( \pm s.e.m.) retinoic acid concentration in medium from cultured unoperated, lens-removed and lens-replaced eyes. The retinoic acid concentration in the medium was calculated from a standard curve generated in parallel for each individual experiment. ${ }^{*} P<0.05$. One-way ANOVA with Tukey's post-hoc comparison. Scale bars: $100 \mu \mathrm{m}$.

Consistent with the idea that RDH10-mediated conversion of vitamin A to retinol acts downstream of the lens to drive expansion of the eye, we found that retinoic acid synthesis is decreased by lensremoved eyes (Fig. 6). Moreover, beads soaked in retinoic acid or retinal, but not vitamin $\mathrm{A}$, rescued the size and morphology of lensremoved eyes (Fig. 7A,B). Eyes from rat embryos made vitamin A deficient after initial induction of the eye has occurred (E10.5 onwards) also display many phenotypic similarities to chicken eyes in which the lens has been removed following initial development of the eye, including failure of vitreous accumulation, retinal folding and anterior segment defects (See and Clagett-Dame, 2009).

RDH10 is the primary enzyme that catalyses the first oxidative reaction in embryonic retinoic acid synthesis: the conversion of vitamin A to retinal (Farjo et al., 2011; Rhinn et al., 2011; Sandell et al., 2007; Shannon et al., 2017). Rdh10 mutant mice die by midgestation (E12-E13), likely due to vascular defects, and display severe defects in the development of multiple tissues and organs, including the eyes. In Rdh10 mutants, the eyes are often not visible from the surface, are smaller than normal, and the cornea and ventral half of the retina fail to develop (Rhinn et al., 2011; Sandell et al., 2007). The eye defects in $R d h 10$ mouse mutants are more severe than we have found in lens-removed chicken eyes. This likely reflects that, in our experiments, $R D H 10$ expression is maintained during initial stages of eye development, prior to lens removal, whereas, in the Rdh10 mouse mutants, RDH10 will be absent from the outset. Consistent with this idea, rescue experiments in vitamin A-deficient rat embryos have demonstrated distinct temporal requirements for vitamin A during eye development. During early stages of eye development, vitamin A is essential for ventral retina formation and closure of the choroidal fissure, and at later stages for development of the vitreous and preventing retinal folding (See and Clagett-Dame, 2009; Wilson et al., 1953). In lens-removed chicken eyes, RDH10 expression also is not lost completely, but is maintained in the RPE (Fig. 2, Fig. S1A), which may alleviate the 

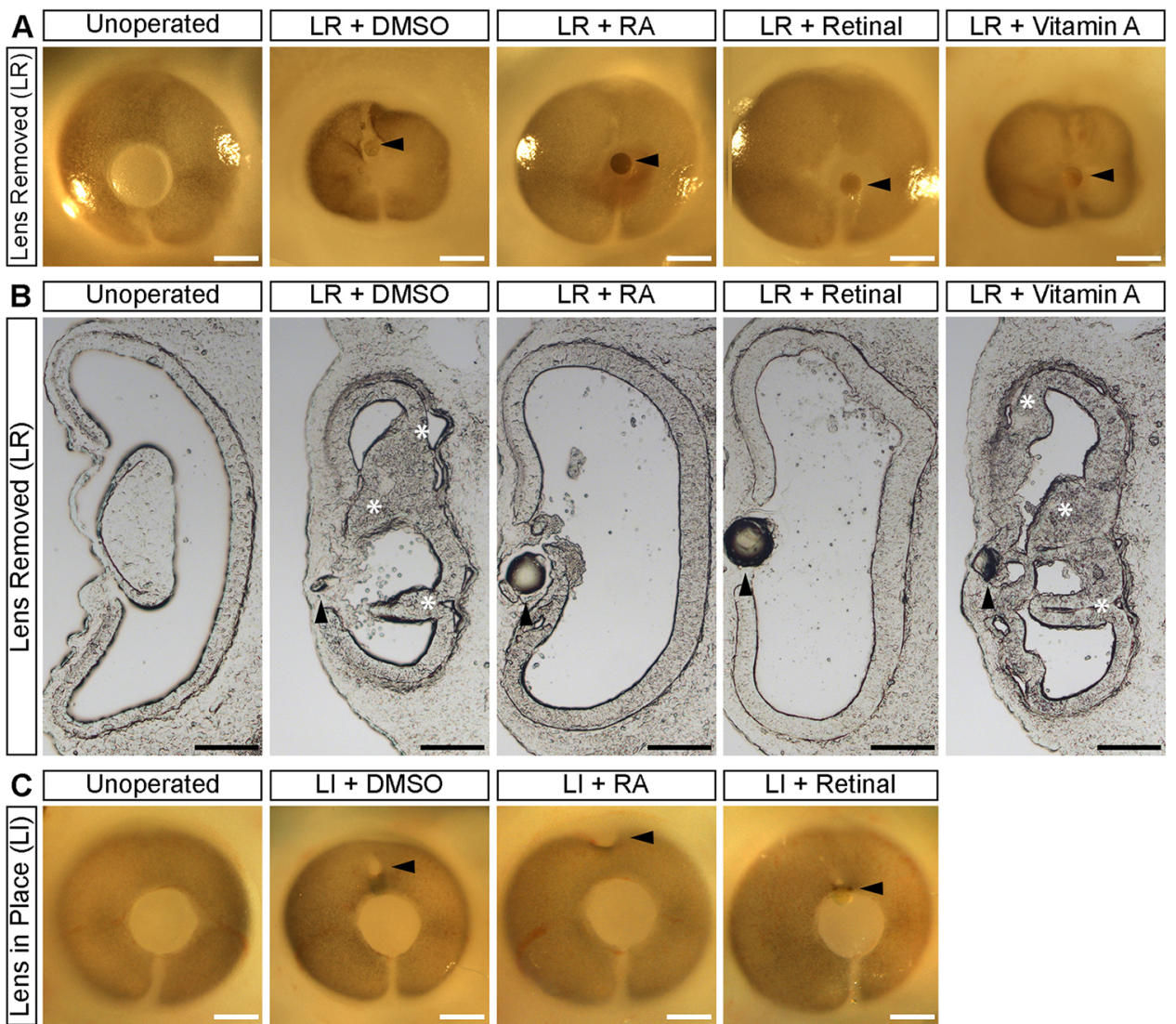

D

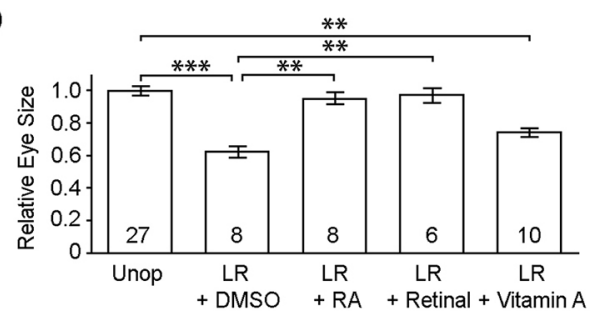

E

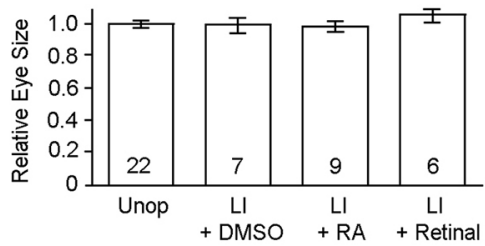

Fig. 7. Exogenous retinoic acid or retinal, but not vitamin A, rescues expansion of lens-removed eyes. Whole-mount views $(A)$ and sections (B) of unoperated contralateral control eyes or eyes in which the lens was removed (LR) at $\mathrm{HH} 23$ and replaced with a bead (arrowheads) soaked in DMSO (vehicle control), $0.1 \mathrm{mg} / \mathrm{ml}$ retinoic acid (RA), $1 \mathrm{mg} / \mathrm{ml}$ retinal or $1 \mathrm{mg} / \mathrm{ml}$ vitamin $\mathrm{A}$ in DMSO, and fixed $24 \mathrm{~h}$ later. The eye is smaller and the retina has become detached and folded (asterisks in B) in eyes in which the lens was replaced with a bead soaked with DMSO or vitamin A, but has similar size and morphology to unoperated eyes following replacement of the lens with a bead soaked in retinoic acid or retinal.

(C) Whole-mount views of untreated contralateral control eyes or eyes, with the lens left in place (LI), implanted with a bead (arrowheads) soaked in DMSO, $0.1 \mathrm{mg} / \mathrm{ml}$ retinoic acid (RA) or $1 \mathrm{mg} / \mathrm{ml}$ retinal, and fixed $24 \mathrm{~h}$ later. (D,E) Mean ( \pm s.e.m.) relative eye size $24 \mathrm{~h}$ after replacement of the lens (D) or after implantation into normal lens-containing eyes $(E)$ of beads soaked in DMSO, $0.1 \mathrm{mg} / \mathrm{ml}$ retinoic acid (RA), $1 \mathrm{mg} / \mathrm{ml}$ retinal or $1 \mathrm{mg} / \mathrm{ml}$ vitamin A at $\mathrm{HH} 23$. Relative eye size was determined for each embryo by calculating the ratio of the mean diameter of the operated eye and contralateral untreated eye. Numbers on bars indicate numbers analysed for each condition. ${ }^{* *} P<0.01$, ${ }^{* * *} P<0.001$. One-way ANOVA with Tukey's post-hoc comparison. Scale bars: $500 \mu \mathrm{m}$ in A,C; $250 \mu \mathrm{m}$ in B. severity of the eye defects. Taken as a whole, our findings are consistent with RDH10-mediated retinoic acid synthesis playing an essential role downstream of the lens in controlling eye expansion. Further experiments will be required to establish whether other lensregulated peripheral retina genes, such as WNT2B and BMP7 (Fig. 1C), also are essential for expansion of the eye acting either in the same pathway, upstream or downstream of $R D H 10$, or in parallel signalling pathways.

The vitreous is a virtually acellular gel-like substance that fills the posterior chamber of the eye and, at E10, comprises $40 \%$ of the weight of the developing chicken eye (Halfter et al., 2008). The vitreous is composed predominately of water $(\sim 98 \%)$ and a loose network of fibrils (collagen fibrils as well as non-collagenous proteins, including versican, fibronectin, tenascin and fibrillin). Collagen II is the major fibrillar collagen of the vitreous and is important for conferring the gel-like properties of the vitreous. Collagen IX localises at regular intervals along the collagen II fibrils and helps link together and regulate the spacing of the collagen II fibrils to form a loose meshwork (Bishop, 2000; Wright and Mayne, 1988; Yada et al., 1990). Through its bound chondroitin sulphate side chains, the major glycosaminoglycan of the avian vitreous, collagen IX also is important for the hydration of the vitreous (Yada et al., 1990). Intravitreal injection of chondroitin sulphate increases eye size in chicken embryos, whereas intravitreal injection of heparin decreases eye size and vitreous body weight through interfering with collagen fibril formation, demonstrating the important relationship between vitreous composition and eye size (Halfter, 2008). Mutations in human collagen II and IX genes cause Stickler syndrome, characteristic phenotypes of which include myopia, vitreoretinal degeneration and retinal detachment (Ahmad et al., 1991; Baker et al., 2011; Nikopoulos et al., 2011; Richards et al., 2006; Van Camp et al., 2006). Owing to the failure of vitreous expansion and the folding of the retina within the vitreal cavity, we have been unable to analyse the composition of the vitreous in lens-removed eyes. Nevertheless, our finding that collagen II and collagen IX levels are decreased in the peripheral retina (presumptive ciliary body region) of lens-removed eyes is consistent with the idea that secretion of collagen II and collagen IX into the vitreous is decreased in lens-removed eyes, and contributes to the failed expansion of the vitreous and, consequently, reduced eye size.

Retinoic acid has a well-characterised role in regulating collagen production in a range of different cell types, including corneal endothelial cells and keratocytes, RPE cells, fibroblasts and chondroctyes (Ahadome et al., 2016; Beach and Kenney, 1983; Cohen et al., 2006; Gouveia and Connon, 2013; Zhang et al., 2017). 

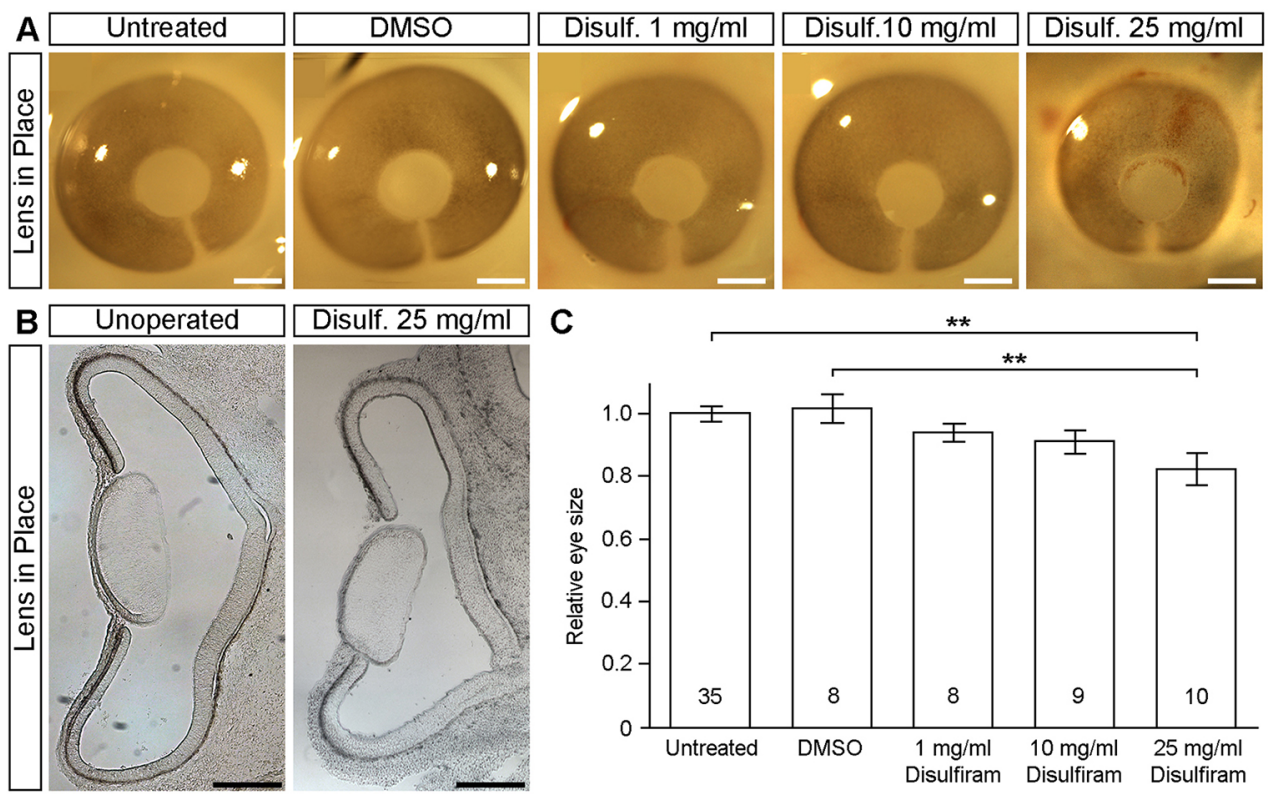

C

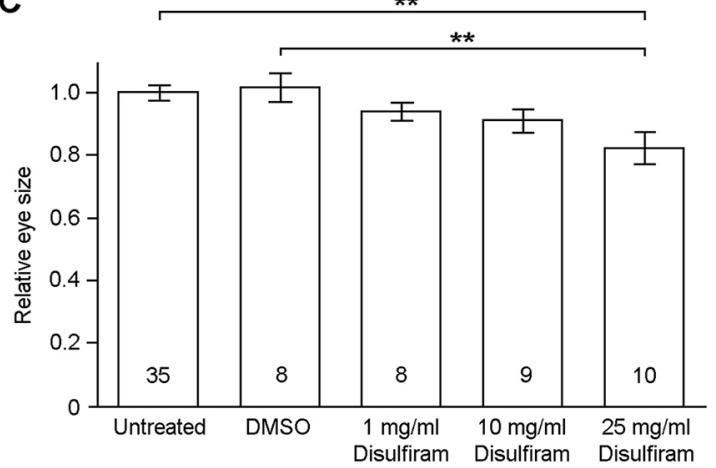

Fig. 8. Inhibiting retinoic acid synthesis reduces eye size. Whole-mount views (A) and sections (B), and mean ( \pm s.e.m.) relative eye size $(C)$ of untreated contralateral control eyes or eyes $24 \mathrm{~h}$ after application of a gelatine sponge soaked in DMSO or disulfiram (Disulf.; 1, 10 or $25 \mathrm{mg} / \mathrm{ml}$ in DMSO) at $\mathrm{HH} 23$. Relative eye size was determined for each embryo by calculating the ratio of the mean diameter of the operated eye and contralateral untreated eye. Numbers on bars indicate numbers analysed for each condition. ${ }^{* *} P<0.01$. One-way ANOVA with Tukey's post-hoc comparison. Scale bars: $500 \mu \mathrm{m}$ in $A ; 250 \mu \mathrm{m}$ in $\mathrm{B}$.
Both direct and indirect activation of collagen genes by retinoic acid has been reported. In chick prehypertrophic chondrocytes, retinoic acid binds to RAREs in the promotor region of the collagen $\mathrm{X}$ gene to directly activate transcription (Cohen et al., 2006). In contrast, retinoic acid-induced stimulation of COL9A1 expression in deer antler chondrocytes occurs indirectly through activation of a BMP2WNT4-RUNX1 pathway (Zhang et al., 2017). Consistent with an indirect mode of action, expression of $B M P 7$ and $W N T 2 B$ also is downregulated in the peripheral retina of lens-removed eyes (Fig. 1C). Moreover, analyses of conditional mouse knockouts lacking Rar genes in the periocular mesenchyme, and Raldh1, Raldh2 and Raldh3 single and triple knockout mice, has demonstrated that retinoic acid acts primarily in a paracrine fashion to regulate eye morphogenesis (Matt et al., 2005; Molotkov et al., 2006).

The identity of the signal(s) released by the lens are not known. Beads soaked in growth factors known to be expressed by the lens, including TGF $\beta 1$, TGF $\beta 2$, FGF2, PDGF, TGF $\alpha$ and BMP7 cannot substitute for the lens in mouse optic cup cultures (Thut et al., 2001). However, knockout of TGF $\beta$ receptor type 2 from neural crest cells has implicated TGF $\beta 2$ released by the lens in the development of the cornea and anterior eye structures, including the ciliary body (Ittner et al., 2005). Although we have shown that beads soaked in retinoic acid can rescue lens-removed eyes, no expression of any of the genes essential for the second step in retinoic acid synthesis (Raldh1, Raldh2 or Raldh3) were detected in the developing lens (Fig. 4B), making it unlikely that retinoic acid is the lens-derived signal. Further experiments will be required to establish the identity of the lens-derived signal(s) and whether $\mathrm{RDH} 10$ is a direct target of these signals.

\section{Conclusions}

The mechanism by which the lens controls eye expansion has remained unknown for over 50 years. We have found that the lens acts indirectly to control eye growth through patterning of the retinal periphery. A key lens-regulated gene in the peripheral retina is $R D H 10$, which encodes an essential enzyme in the retinoic acid synthesis pathway. Retinoic acid synthesis by lens-removed eyes is decreased and adding exogenous retinoic acid, or its immediate precursor retinal, is sufficient to rescue eye size as well as production of vitreal collagens in the absence of the lens. These data provide a mechanistic explanation for the requirement of the lens in establishing normal eye size and an unexpected link between two classical factors long known to be important for eye development: the lens and retinoic acid signalling.

\section{MATERIALS AND METHODS Chicken embryos}

Fertilised White Leghorn chicken embryos were obtained from Henry Stewart (Herefordshire, UK). Eggs were incubated on their sides in a humidified incubator at $37^{\circ} \mathrm{C}$ until the desired embryological stage. All embryos were staged according to Hamburger and Hamilton $(\mathrm{HH}$; Hamburger and Hamilton, 1951). All experiments were performed in accordance with University of Aberdeen and UK Home Office Guidelines.

\section{In ovo lens removal and drug application}

Lenses were removed from $\mathrm{HH} 23$ chicken embryos according to the method of Coulombre and Coulombre, (1964). The egg was windowed and the membranes covering the embryo removed around the eye. Using forceps, a small slit was made in the eye opposite the ventral fissure, the lens grasped and removed from the eye. As a damage control, lenses were removed and replaced immediately. The eggs were sealed with Sellotape and re-incubated until the desired postoperative time point.

AG1-X2 beads (Bio-Rad) were soaked in $10 \mu \mathrm{l}$ of either DMSO, retinoic acid $(0.1 \mathrm{mg} / \mathrm{ml}$; Sigma-Aldrich), retinal $(1 \mathrm{mg} / \mathrm{ml}$; Sigma-Aldrich) or retinol (vitamin A; $1 \mathrm{mg} / \mathrm{ml}$; Sigma-Aldrich) in DMSO for $1 \mathrm{~h}$ in the dark and washed with DMEM. The lens was removed from $\mathrm{HH} 23$ embryos and a bead implanted under the cornea close to the optic cup rim. Beads were also implanted in normal lens-containing eyes. To block retinoic acid signalling, small pieces of gelatine sponge (Sigma-Aldrich) were soaked in DMSO or disulfiram (1, 10 or $25 \mathrm{mg} / \mathrm{ml}$ in DMSO; Sigma-Aldrich) for $1 \mathrm{~h}$, washed with DMEM and applied on top of normal, lens-containing HH23 eyes. Embryos were re-incubated for $24 \mathrm{~h}$ before imaging and fixation.

\section{Counts of total retinal cell number}

Lenses were removed or removed and replaced immediately from $\mathrm{HH} 23$ chicken eyes and the eggs re-incubated for $24 \mathrm{~h}$. If still present, the lens was removed and the whole eye excised from the orbit and transferred to HBSS without calcium $/$ magnesium (Thermo Fisher Scientific) at $37^{\circ} \mathrm{C}$ for $30 \mathrm{~min}$. The RPE was removed, the isolated retina incubated in $200 \mu$ trypsin for $20 \mathrm{~min}$ (Thermo Fisher Scientific) and the cells dissociated. The cell suspension was centrifuged, excess media removed and the cells re-suspended in $600 \mu \mathrm{l} \mathrm{DMEM} / \mathrm{F} 12$ (Thermo Fisher Scientific). Using a 

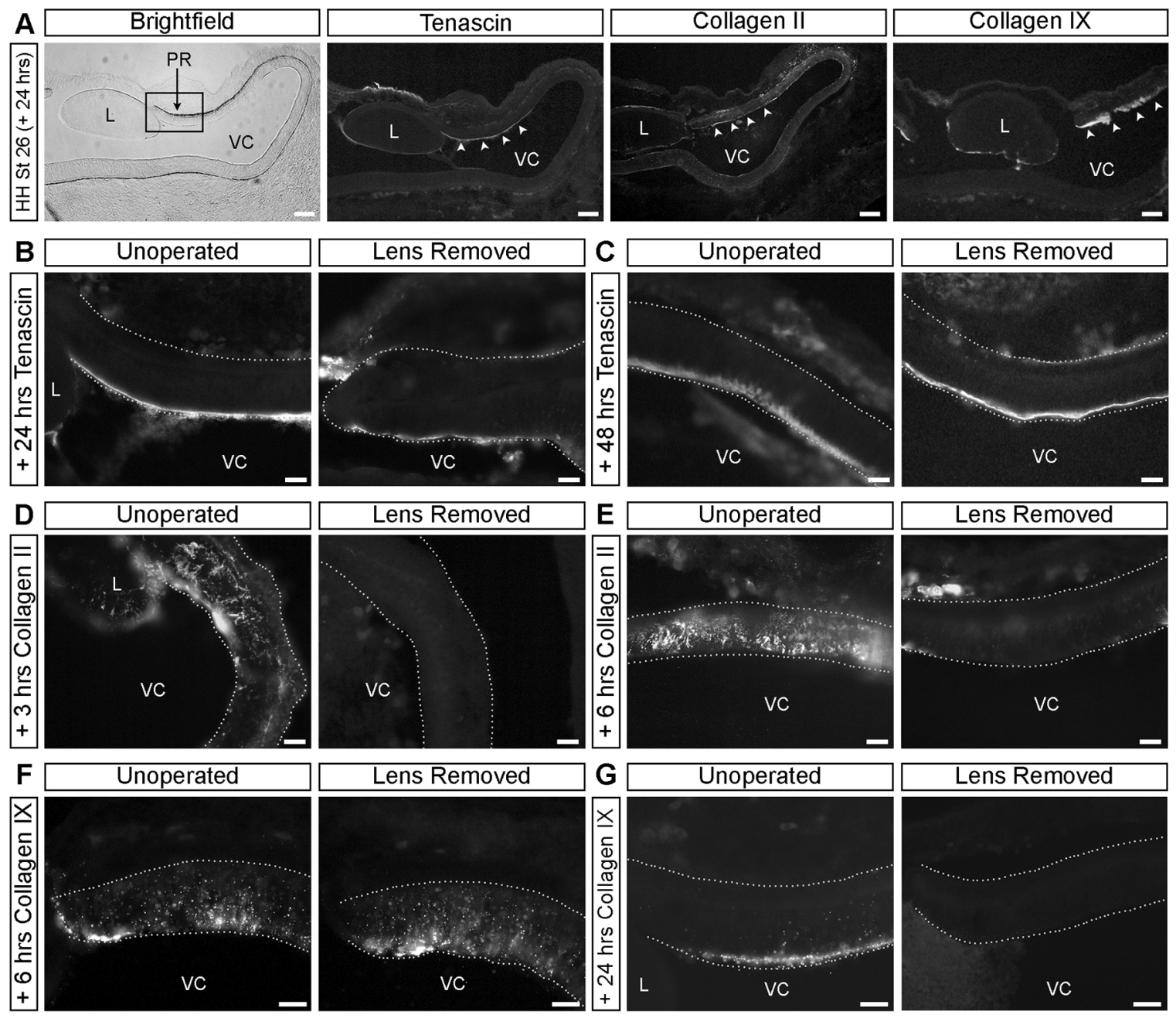

Fig. 9. The lens regulates collagen II and collagen IX, but not tenascin C, protein localisation to the peripheral retina. (A) Sections of HH26 unoperated contralateral control eyes imaged using bright-field or following immunofluorescent staining with antibodies specific for tenascin C, collagen II or collagen IX. White arrowheads indicate protein localisation in the peripheral retina (presumptive ciliary body region). (B-G) Horizontal sections of unoperated contralateral control eyes or eyes in which the lens was removed at $\mathrm{HH} 23$ and fixed 3, 6, 24 or $48 \mathrm{~h}$ later, and stained using antibodies specific for tenascin C (B,C), collagen II $(D, E)$ or collagen IX $(F, G)$. Images are of the peripheral retina region indicated by the box in the bright-field image in $A$. Dotted lines indicate the outline of the retina. L, lens; PR, peripheral retina; VC, vitreal cavity. Scale bars: $100 \mu \mathrm{m}$ in A; $25 \mu \mathrm{m}$ in B-G.

haemocytometer, cells were counted, two samples per eye, to calculate the average number of cells within each retina (Fig. S2A)

\section{Cryosectioning}

Embryonic heads were fixed in $4 \%$ formaldehyde in PBS overnight and cryo-protected in 30\% sucrose in PBS. The heads were placed in the desired orientation in a mould containing Cryo-M-Bed (TAAB) and frozen at $-20^{\circ} \mathrm{C}$. Sections were cut at $25 \mu \mathrm{m}$ on a cryostat (Leica) and mounted on SuperFrost Plus slides (VWR). The slides were left to air dry overnight and stored at $-20^{\circ} \mathrm{C}$.

\section{In situ hybridisation}

Frozen sections were thawed at room temperature, washed with PBT (PBS $+0.1 \%$ Tween-20; Sigma-Aldrich), post-fixed with $4 \%$ formaldehyde in PBS for $20 \mathrm{~min}$, washed with PBT and incubated in hybridisation solution $\left[50 \%\right.$ formamide, $5 \times \mathrm{SSC}\left(750 \mathrm{mM} \mathrm{NaCl}, 75 \mathrm{mM} \mathrm{Na}_{3}\right.$ Citrate dihydrate at $\mathrm{pH} 4.5$ ), $50 \mu \mathrm{g} / \mathrm{ml}$ tRNA, $1 \%$ SDS (sodium dodecyl sulphate), $50 \mu \mathrm{g} / \mathrm{ml}$ heparin] for $60 \mathrm{~min}$ at $65^{\circ} \mathrm{C}$. Diluted riboprobes $(15 \mu \mathrm{l} / \mathrm{ml}$ of hybridisation solution) were added to each slide and hybridised overnight at $65^{\circ} \mathrm{C}$. Slides were washed three times with $50 \%$ formamide, $5 \times \mathrm{SSC}$ and $1 \%$ SDS at $65^{\circ} \mathrm{C}$, three times with $50 \%$ formamide and $2 \times \mathrm{SSC}(\mathrm{pH} 4.5)$ at $60^{\circ} \mathrm{C}$, washed with TBST (Tris-buffered saline $+1 \%$ Tween-20) at room temperature and blocked with $10 \%$ sheep serum in TBST. Slides were incubated with anti-digoxigenin-AP fragments (Sigma-Aldrich; 1:2000 in $1 \%$ sheep serum in TBST) overnight at $4^{\circ} \mathrm{C}$, washed extensively with TBST, three times with NTMT [100 mM NaCl, $100 \mathrm{mM}$ Tri-HCl ( $\mathrm{pH} 9.5$ ), $50 \mathrm{mM} \mathrm{MgCl} 2,1 \%$ Tween-20] and incubated in colour reaction $[$ NTMT $+337.5 \mu \mathrm{g} / \mathrm{ml}$ Nitrotetrazolium Blue chloride (NBT; SigmaAldrich) $+175 \mu \mathrm{g} / \mathrm{ml}$ 5-bromo-4-chlor-3-indolyl-phosphate, 4-toludine salt (BCIP; Sigma-Aldrich)]. Once the reaction was judged complete, the slides were washed with PBS, post-fixed with $4 \%$ formaldehyde in PBS and mounted in $90 \%$ glycerol in PBS.

To generate templates for the RALDH1-RALDH3 (ALDH1A1-3), COL9A1, COL9A3, tenascin C (TNC), OTX1 and WNT2B riboprobes, RNA was extracted from $\mathrm{HH} 23$ chicken eyes using the Qiagen RNeasy Mini kit and cDNA synthesised using Superscript III (Thermo Fisher Scientific) according to the manufacturers' instructions. DNA fragments were isolated by PCR $\left(94^{\circ} \mathrm{C}\right.$ for $5 \mathrm{~min}, 35$ cycles of $94^{\circ} \mathrm{C}$ for $40 \mathrm{~s}, 55^{\circ} \mathrm{C}$ for $1 \mathrm{~min}, 72^{\circ} \mathrm{C}$ for $90 \mathrm{~s}$, followed by a final extension at $72^{\circ} \mathrm{C}$ for $5 \mathrm{~min}$ ) and cloned into pGEM-T Easy (Promega). The following primers were used: $R A L D H 1$ forward, TTGCAGAAGGTGACAAGGCA; reverse, ACCCTTGTTTCCCCATGGAC; $R A L D H 2$ forward, ATGCATCGGAAAGAGGCCAA; reverse, CAGCTACCACCCAAAGTC; RALDH3 forward, TCTGAGGGGTTTGGAGGTGA; reverse, CACCACACTCCAGCTTAGCA; COL9A1 

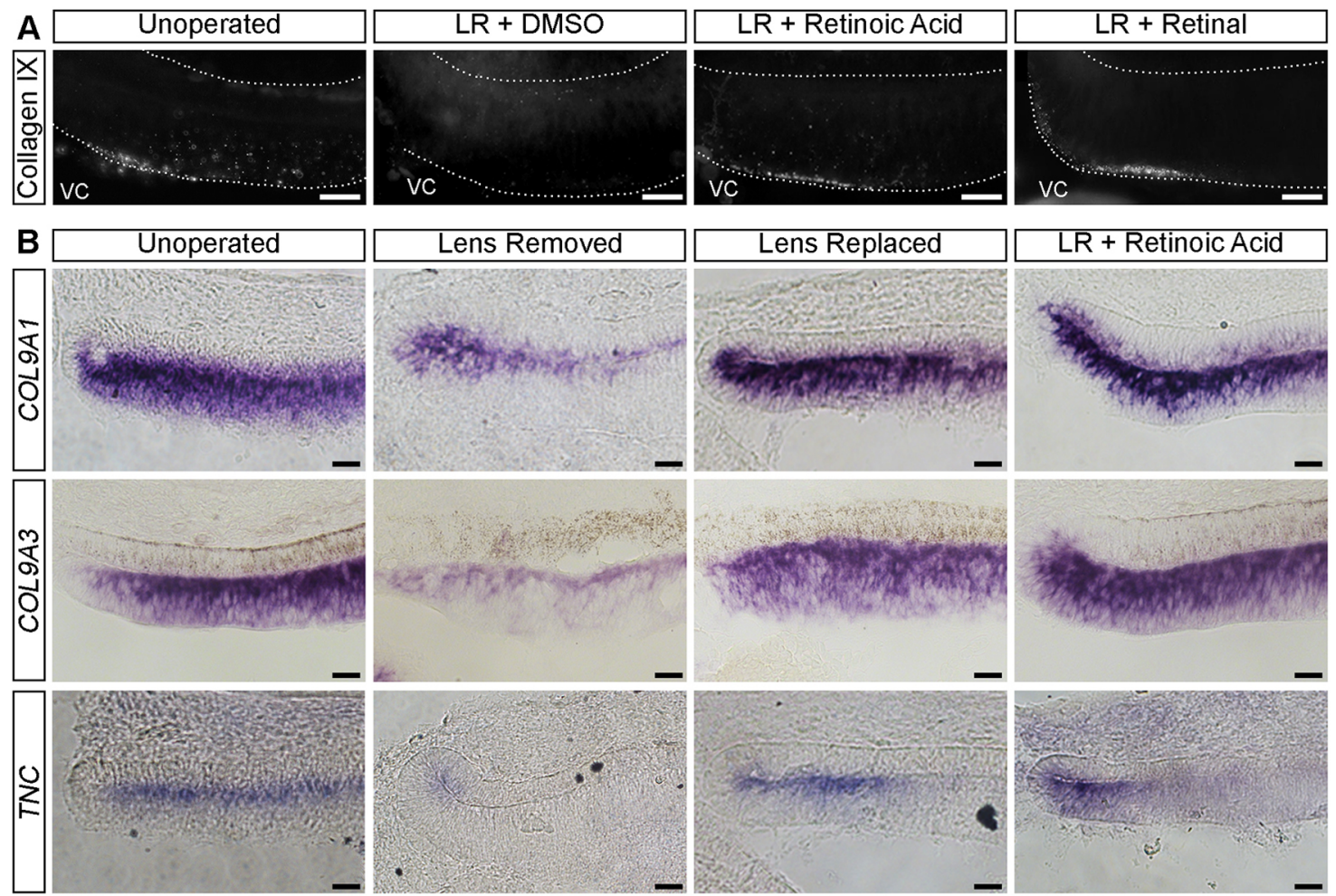

C

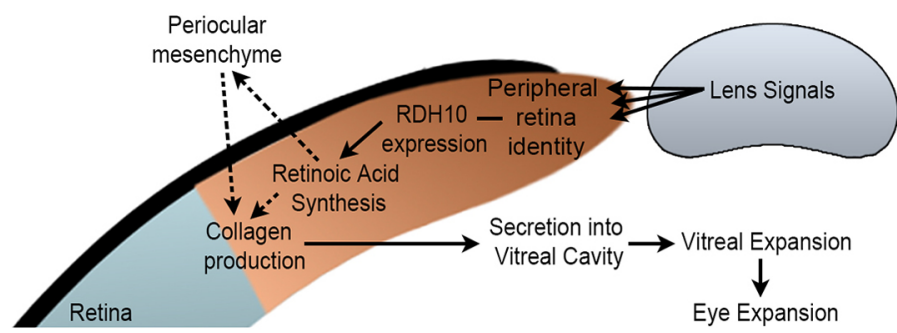

Fig. 10. Retinoic acid regulates collagen IX synthesis in the peripheral retina. (A) Immunofluorescence for collagen IX on representative sections of unoperated contralateral control eyes or eyes in which the lens was removed (LR) at HH23 and replaced with a bead soaked in $1 \%$ DMSO (vehicle control), $0.1 \mathrm{mg} / \mathrm{ml}$ retinoic acid or $1 \mathrm{mg} / \mathrm{ml}$ retinal and fixed $24 \mathrm{~h}$ later. Dotted lines indicate the outline of the retina. VC, vitreal cavity. (B) In situ hybridisation with probes specific for COL9A1, COL9A3 or TNC (tenascin C) on sections of unoperated contralateral control eyes or eyes in which the lens was removed, removed and replaced immediately, or replaced with a bead soaked in retinoic acid $(0.1 \mathrm{mg} / \mathrm{ml})$ and fixed $24 \mathrm{~h}$ later. Scale bars: $25 \mu \mathrm{m}$. (C) Schematic illustrating the proposed lens-regulated mechanism controlling expansion of the eye. Signals from the lens maintain peripheral retina identity, including expression of $R D H 10$ in the presumptive ciliary body region (brown). $\mathrm{RDH} 10$ is required for production of retinoic acid, which, in turn, controls synthesis of vitreal collagens and eye expansion. Further experiments will be required to establish whether retinoic acid regulates collagen production directly or acts in a paracrine fashion (dotted arrows).

forward, AGTCATTCTGGGTGCTCGTC; reverse, GGAGCTCACCACAACCTTCT; COL9A3 forward, AACTGGGTCCAAAAGGTGCT; reverse, CCCATGCAAGCTGATGTGTC; TNC forward, AGACTGGCTGGGATGGTTTC; reverse, TCGGGTTCTGCCTCTGTTGTA; OTX1 forward, CACCGCGCTGCCCTTCAACT; reverse, GTGCAGCCCAGGAGCGTCAG; WNT2B forward, CCCGCGGATTTGCCTTCCCT; reverse, TGGTCCAACCACTCGGCCCT. Other probes used were: TBX5 (Therapontos et al., 2009), $c V A X$ (a gift from Professor Paola Bovolenta, Center for Molecular Biology Severo Ochoa, CSIC-UAM, Madrid, Spain.), BMP7 (Yang et al., 1997) and RDH10 (Reijntjes et al., 2010).

\section{Real-time PCR}

RNA was extracted from chicken eyes using the Qiagen RNeasy mini kit and cDNA prepared using the Superscript III first-strand synthesis system (Thermo Fisher Scientific) according to the manufacturer's instructions. The final yield was diluted 1:5 with $\mathrm{H}_{2} \mathrm{O}$. A master mix was prepared containing for each sample SYBR Green 1 (10 $\mu$; Sigma-Aldrich), $\mathrm{H}_{2} \mathrm{O}(5 \mu \mathrm{l})$ and the relevant primers ( $2 \mu \mathrm{l}$ of a $10 \mu \mathrm{M}$ stock; RDH10 forward, GCACTGCTGGAGTAGAGGATT; reverse, CGGTGGAAGGAAAGGCTCAA; WNT2B forward, GATGGACAAGTCAGCAGGCTC; reverse, CCTTTTGGGCGCTTTACACG. GAPDH was used as a reference gene: forward, TGCTAAGGCTGTGGGGAAAG; reverse, CAGCAGCCTTCACTACCCTC). For each sample, $3 \mu 1$ of cDNA was added to a well of a 384-well plate followed by $17 \mu \mathrm{l}$ of the mastermix. Experiments were run using the SYBR-Green 384-I protocol on a LightCycler 480 Real-Time PCR machine. Results were analysed using the Light Cycler software and Microsoft Excel. For each sample, three independent wells were run. Results are the mean from three independent experiments.

\section{Immunofluorescence}

Frozen sections were thawed at room temperature, blocked with $10 \%$ goat serum (Sigma-Aldrich), 0.2\% Triton X-100 (Sigma-Aldrich) in PBS and incubated in primary antibodies diluted in blocking solution overnight at $4{ }^{\circ} \mathrm{C}$. The following antibodies were used: anti-islet1 and -islet2 (Developmental Studies Hybridoma Bank 39.4D5, 1:50), anti-phosphohistone H3 (Millipore 06-570; 1:100), anti-collagen IX (Developmental Studies Hybridoma Bank 2B9; 1:5), anti-collagen II (Developmental Studies Hybridoma Bank II-II6B3; 1:50) and anti-tenascin C (Developmental Studies Hybridoma 
Bank M1-B4; 1:50). Slides were washed with PBS and incubated overnight with the appropriate secondary antibody (goat anti-mouse $\mathrm{IgG}-\mathrm{Cy} 3$, goat anti-mouse IgM-Cy3 or goat anti-rabbit IgG-Cy3; Jackson Immunoresearch; 1:500 in 1\% goat serum in PBS). Slides were washed with PBS and mounted in Vectashield (Vector Laboratories).

\section{Retinoic acid bioassay}

Lenses were removed or removed and replaced immediately from $\mathrm{HH} 23$ chicken eyes and the eggs re-incubated for $24 \mathrm{~h}$. Control and lens-removed eyes were removed from the orbit and incubated in four-well plates (Nunc) 5 eyes/well in serum-free medium [DMEM/F12, 1\% penicillin/streptomycin, $1 \%$ bovine serum albumin, ITS supplement (Sigma-Aldrich); $500 \mu \mathrm{l} /$ well] overnight. Sil-15 cells (a gift from Prof. Peter McCaffery, University of Aberdeen, UK) were plated at a density of 80,000 cells/well in a 96-well plate coated with $0.2 \%$ gelatine (Sigma-Aldrich) in PBS and incubated until confluent. Medium conditioned by dissected eyes was added to the confluent cells, $100 \mu 1 /$ well, and incubated overnight. On the same plate, a standard curve of retinoic acid was included in triplicates at concentrations from $10^{-12.5}$ $\mathrm{M}$ to $10^{-7} \mathrm{M}$ at $10^{-0.5} \mathrm{M}$ intervals as positive controls. All wells were fixed in $1 \%$ gluteraldehyde (Sigma-Aldrich) $/ 25 \mathrm{mM} \mathrm{MgCl}_{2}$ and washed with PBS. Reaction solution $[1 \mathrm{mg} / \mathrm{ml} \mathrm{X}$-gal, $5 \mathrm{mM}$ potassium ferric-cyanide (SigmaAldrich), $5 \mathrm{mM}$ potassium ferro-cyanide (Sigma-Aldrich), $2 \mathrm{mM}$ magnesium chloride; $100 \mu \mathrm{ll}$ was added to each well and incubated at $37^{\circ} \mathrm{C}$ overnight. The absorbance was read on an Emax microplate reader at $650 \mathrm{~nm}$.

\section{Image capture and analysis}

Images of whole eyes were captured using a Nikon SMZ1500 microscope with Nikon DS-SM camera. Images of immunofluorescence staining and bright-field sections were captured using a Zeiss Axiophot microscope with Nikon DXM1200 camera and ACT-1 software and SiL-15 cells using an Evos XL microscope. For quantification of eye size, Image J (https://imagej. nih.gov/ij/) was used to measure the horizontal and vertical diameters of operated and control eyes and mean eye diameter calculated (Fig. 2B). Phosphohistone-H3-positive mitotic cells were counted manually from images of stained sections captured at $20 \times$. Retinal length in each section was measured using Image $J$ and the number of labelled cells per $\mathrm{mm}$ of retina calculated. To quantify the number of phosphohistone-H3-positive cells within the peripheral retina, all labelled cells in the most peripheral $200 \mu \mathrm{m}$ of the retina were counted. Figures were prepared using Adobe Photoshop.

All data sets were analysed using the Shapiro-Wilk Normality Test and found to be normally distributed. Statistical comparisons were made by oneway ANOVA with Tukey post-hoc analysis or Student's unpaired $t$-test.

\section{Acknowledgements}

We thank Timothy Davies, William Garrett, Louis-Pierre Girard, Naseem Givzad, Jennifer McClure and Katherine McLellan for assistance with experiments; Peter McCaffery for providing the Sil-15 retinoic acid reporter cells and his advice on designing the retinoic acid quantification assay; Verónica Murcia-Belmonte for helpful comments on the manuscript; and the staff of the University of Aberdeen Microscopy and Histology Facility for imaging advice and assistance. The monoclonal antibodies 2B9, II-II6B3, 39.4D5 and M1-B4, developed by Drs Halfter, Linsenmayer, Jessell/ Brenner-Morton and Fambrough, respectively, were obtained from the Developmental Studies Hybridoma Bank, created by the NICHD of the NIH and maintained at the University of lowa, Department of Biology, lowa City, IA 52242.

\section{Competing interests}

The authors declare no competing or financial interests.

\section{Author contributions}

Conceptualization: J.N.S., H.M.W., H.T., J.M.C., N.V., L.E.; Methodology: J.N.S., H.M.W., H.T., J.M.C., N.V., L.E.; Formal analysis: J.N.S., H.M.W., H.T., N.V., L.E.; Investigation: J.N.S., H.M.W., H.T., N.V., L.E.; Writing - original draft: J.N.S., L.E.; Writing - review \& editing: H.M.W., H.T., J.M.C., N.V.; Supervision: J.M.C., N.V., L.E.; Funding acquisition: J.M.C., N.V., L.E.

\section{Funding}

This research was funded by a Biotechnology and Biological Sciences Research Council (BBSRC) PhD studentship to H.M.W., by a University of Aberdeen Institute of Medical Sciences PhD Studentship to J.N.S., and by a grant from the University of Aberdeen Development Trust [OL 989 to L.E. and J.M.C.].
Supplementary information

Supplementary information available online at

http://dev.biologists.org/lookup/doi/10.1242/dev.167171.supplemental

\section{References}

Ahadome, S. D., Abraham, D. J., Rayapureddi, S., Saw, V. P., Saban, D. R. Calder, V. L., Norman, J. T., Ponticos, M., Daniels, J. T. and Dart, J. K. (2016) Aldehyde dehydrogenase inhibition blocks mucosal fibrosis in human and mouse ocular scarring. JCl Insight 1, e87001.

Ahmad, N. N., Ala-Kokko, L., Knowlton, R. G., Jimenez, S. A., Weaver, E. J., Maguire, J. I., Tasman, W. and Prockop, D. J. (1991). Stop codon in the procollagen II gene (COL2A1) in a family with the Stickler syndrome (arthro-ophthalmopathy). Proc. Natl. Acad. Sci. USA 88, 6624-6627.

Baker, S., Booth, C., Fillman, C., Shapiro, M., Blair, M. P., Hyland, J. C. and Ala-Kokko, L. (2011). A loss of function mutation in the COL9A2 gene causes autosomal recessive Stickler syndrome. Am. J. Med. Genet. A 155A, 1668-1672. Beach, R. S. and Kenney, M. C. (1983). Vitamin A augments collagen production by corneal endothelial cells. Biochem. Biophys. Res. Commun. 114, 395-402.

Beebe, D. C. and Coats, J. M. (2000). The lens organizes the anterior segment specification of neural crest cell differentiation in the avian eye. Dev. Biol. 220, 424-431.

Bishop, P. N. (2000). Structural macromolecules and supramolecular organisation of the vitreous gel. Prog. Retin. Eye Res. 19, 323-344.

Bishop, P. N., Takanosu, M., Le Goff, M. and Mayne, R. (2002). The role of the posterior ciliary body in the biosynthesis of vitreous humour. Eye (Lond) $16,454-460$

Blixt, A., Mahlapuu, M., Aitola, M., Pelto-Huikko, M., Enerback, S. and Carlsson, P. (2000). A forkhead gene, FoxE3, is essential for lens epithelial proliferation and closure of the lens vesicle. Genes Dev. 14, 245-254.

Breitman, M. L., Clapoff, S., Rossant, J., Tsui, L. C., Glode, L. M., Maxwell, I. H. and Bernstein, A. (1987). Genetic ablation: targeted expression of a toxin gene causes microphthalmia in transgenic mice. Science 238, 1563-1565.

Breitman, M. L., Bryce, D. M., Giddens, E., Clapoff, S., Goring, D., Tsui, L. C. Klintworth, G. K. and Bernstein, A. (1989). Analysis of lens cell fate and eye morphogenesis in transgenic mice ablated for cells of the lens lineage. Development 106, 457-463.

Cho, S.-H. and Cepko, C. L. (2006). Wnt2b/beta-catenin-mediated canonical Wnt signaling determines the peripheral fates of the chick eye. Development 133, 3167-3177.

Cohen, A. J., Lassova, L., Golden, E. B., Niu, Z. and Adams, S. L. (2006). Retinoids directly activate the collagen $X$ promoter in prehypertrophic chondrocytes through a distal retinoic acid response element. J. Cell. Biochem. 99, 269-278.

Collinson, J. M., Quinn, J. C., Buchanan, M. A., Kaufman, M. H., Wedden, S. E., West, J. D. and Hill, R. E. (2001). Primary defects in the lens underlie complex anterior segment abnormalities of the Pax6 heterozygous eye. Proc. Natl. Acad. Sci. USA 98, 9688-9693.

Coulombre, A. J. (1956). The role of intraocular pressure in the development of the chick eye. 1. Control of eye size. J. Exp. Zool. 133, 211-225.

Coulombre, A. J. and Coulombre, J. L. (1964). Lens development. I. role of the lens in eye growth. J. Exp. Zool. 156, 39-47.

Dhawan, R. R. and Beebe, D. C. (1994). Differential localization of collagen type IX isoform messenger RNAs during early ocular development. Invest. Ophthalmol. Vis. Sci. 35, 470-478.

Duester, G., Mic, F. A. and Molotkov, A. (2003). Cytosolic retinoid dehydrogenases govern ubiquitous metabolism of retinol to retinaldehyde followed by tissue-specific metabolism to retinoic acid. Chem. Biol. Interact. 143-144, 201-210

Farjo, K. M., Moiseyev, G., Nikolaeva, O., Sandell, L. L., Trainor, P. A. and Ma, J.-X. (2011). RDH10 is the primary enzyme responsible for the first step of embryonic Vitamin A metabolism and retinoic acid synthesis. Dev. Biol. 357, 347-355.

Genis-Galvez, J. M., Santos-Gutierrez, L. and Rios-Gonzalez, A. (1967). Causal factors in corneal development: an experimental analysis in the chick embryo. Exp. Eye Res. 6, 48-56.

Gouveia, R. M. and Connon, C. J. (2013). The effects of retinoic acid on human corneal stromal keratocytes cultured in vitro under serum-free conditions. Invest. Ophthalmol. Vis. Sci. 54, 7483-7491.

Halfter, W. (2008). Change in embryonic eye size and retinal cell proliferation following intravitreal injection of glycosaminoglycans. Invest. Ophthalmol. Vis. Sci. 49, 3289-3298.

Halfter, W., Dong, S., Schurer, B., Ring, C., Cole, G. J. and Eller, A. (2005) Embryonic synthesis of the inner limiting membrane and vitreous body. Invest. Ophthalmol. Vis. Sci. 46, 2202-2209.

Halfter, W., Winzen, U., Bishop, P. N. and Eller, A. (2006). Regulation of eye size by the retinal basement membrane and vitreous body. Invest. Ophthalmol. Vis. Sci. 47, 3586-3594.

Halfter, W., Dong, S., Dong, A., Eller, A. W. and Nischt, R. (2008). Origin and turnover of ECM proteins from the inner limiting membrane and vitreous body. Eye (Lond) 22, 1207-1213. 
Hamburger, V. and Hamilton, H. L. (1951). A series of normal stages in the development of the chick embryo. J. Morphol. 88, 49-92.

Ittner, L. M., Wurdak, H., Schwerdtfeger, K., Kunz, T., Ille, F., Leveen, P. Hjalt, T. A., Suter, U., Karlsson, S., Hafezi, F. et al. (2005). Compound developmental eye disorders following inactivation of TGFbeta signaling in neuralcrest stem cells. J. Biol. 4, 11.

Johnson, B. L. and Cheng, K. P. (1997). Congenital aphakia: a clinicopathologic report of three cases. J. Pediatr. Ophthalmol. Strabismus 34, 35-39.

Kubo, F. and Nakagawa, S. (2009). Hairy1 acts as a node downstream of Wnt signaling to maintain retinal stem cell-like progenitor cells in the chick ciliary marginal zone. Development 136, 1823-1833.

Kubo, F., Takeichi, M. and Nakagawa, S. (2003). Wnt2b controls retinal cel differentiation at the ciliary marginal zone. Development 130, 587-598.

Linsenmayer, T. F., Gibney, E., Gordon, M. K., Marchant, J. K., Hayashi, M. and Fitch, J. M. (1990). Extracellular matrices of the developing chick retina and cornea. Localization of mRNAs for collagen types II and IX by in situ hybridization. Invest. Ophthalmol. Vis. Sci. 31, 1271-1276.

Maden, M., Blentic, A., Reijntjes, S., Seguin, S., Gale, E. and Graham, A. (2007) Retinoic acid is required for specification of the ventral eye field and for Rathke's pouch in the avian embryo. Int. J. Dev. Biol. 51, 191-200.

Martinez-Morales, J. R., Signore, M., Acampora, D., Simeone, A. and Bovolenta, P. (2001). Otx genes are required for tissue specification in the developing eye. Development 128, 2019-2030.

Matt, N., Dupe, V., Garnier, J. M., Dennefeld, C., Chambon, P., Mark, M. and Ghyselinck, N. B. (2005). Retinoic acid-dependent eye morphogenesis is orchestrated by neural crest cells. Development 132, 4789-4800.

Molotkov, A., Molotkova, N. and Duester, G. (2006). Retinoic acid guides eye morphogenetic movements via paracrine signaling but is unnecessary for retina dorsoventral patterning. Development 133, 1901-1910.

Nikopoulos, K., Schrauwen, I., Simon, M., Collin, R. W. J., Veckeneer, M., Keymolen, K., Van Camp, G., Cremers, F. P. M. and van den Born, L. I. (2011) Autosomal recessive Stickler syndrome in two families is caused by mutations in the COL9A1 gene. Invest. Ophthalmol. Vis. Sci. 52, 4774-4779.

Reijntjes, S., Zile, M. H. and Maden, M. (2010). The expression of Stra6 and Rdh10 in the avian embryo and their contribution to the generation of retinoid signatures. Int. J. Dev. Biol. 54, 1267-1275.

Rhinn, M., Schuhbaur, B., Niederreither, K. and Dolle, P. (2011). Involvement of retinol dehydrogenase 10 in embryonic patterning and rescue of its loss of function by maternal retinaldehyde treatment. Proc. Natl. Acad. Sci. USA 108, 16687-16692.

Richards, A. J., Laidlaw, M., Whittaker, J., Treacy, B., Rai, H., Bearcroft, P., Baguley, D. M., Poulson, A., Ang, A., Scott, J. D. et al. (2006). High efficiency of mutation detection in type 1 stickler syndrome using a two-stage approach: vitreoretinal assessment coupled with exon sequencing for screening COL2A1. Hum. Mutat. 27, 696-704.

Sandell, L. L., Sanderson, B. W., Moiseyev, G., Johnson, T., Mushegian, A., Young, K., Rey, J.-P., Ma, J. X., Staehling-Hampton, K. and Trainor, P. A (2007). RDH10 is essential for synthesis of embryonic retinoic acid and is required for limb, craniofacial, and organ development. Genes Dev. 21, 1113-1124.

See, A. W.-M. and Clagett-Dame, M. (2009). The temporal requirement for vitamin A in the developing eye: mechanism of action in optic fissure closure and new roles for the vitamin in regulating cell proliferation and adhesion in the embryonic retina. Dev. Biol. 325, 94-105.
Semina, E. V., Murray, J. C., Reiter, R., Hrstka, R. F. and Graw, J. (2000) Deletion in the promoter region and altered expression of Pitx3 homeobox gene in aphakia mice. Hum. Mol. Genet. 9, 1575-1585.

Shannon, S. R., Moise, A. R. and Trainor, P. A. (2017). New insights and changing paradigms in the regulation of vitamin $\mathrm{A}$ metabolism in development. Wiley Interdiscip Rev. Dev. Biol. 6, e264.

Therapontos, C., Erskine, L., Gardner, E. R., Figg, W. D. and Vargesson, N. (2009). Thalidomide induces limb defects by preventing angiogenic outgrowth during early limb formation. Proc. Natl. Acad. Sci. USA 106 8573-8578

Thut, C. J., Rountree, R. B., Hwa, M. and Kingsley, D. M. (2001). A large-scale in situ screen provides molecular evidence for the induction of eye anterior segment structures by the developing lens. Dev. Biol. 231, 63-76.

Tickle, C., Lee, J. and Eichele, G. (1985). A quantitative analysis of the effect of all-trans-retinoic acid on the pattern of chick wing development. Dev. Biol. 109, 82-95.

Van Camp, G., Snoeckx, R. L., Hilgert, N., van den Ende, J., Fukuoka, H, Wagatsuma, M., Suzuki, H., Smets, R. M., Vanhoenacker, F., Declau, F. et al. (2006). A new autosomal recessive form of Stickler syndrome is caused by a mutation in the COL9A1 gene. Am. J. Hum. Genet. 79, 449-457.

Vermot, J. and Pourquié, O. (2005). Retinoic acid coordinates somitogenesis and left-right patterning in vertebrate embryos. Nature 435, 215-220.

Wagner, M., Han, B. and Jessell, T. M. (1992). Regional differences in retinoid release from embryonic neural tissue detected by an in vitro reporter assay. Development 116, 55-66.

Warkany, J. and Schraffenberger, E. (1946). Congenital malformations induced in rats by maternal vitamin A deficiency; defects of the eye. Arch Ophthal 35, 150-169.

Wilson, J. G., Roth, C. B. and Warkany, J. (1953). An analysis of the syndrome of malformations induced by maternal vitamin A deficiency. Effects of restoration of vitamin A at various times during gestation. Am. J. Anat. 92, 189-217.

Wright, D. W. and Mayne, R. (1988). Vitreous humor of chicken contains two fibrillar systems: an analysis of their structure. J. Ultrastruct. Mol. Struct. Res. 100, 224-234

Yada, T., Suzuki, S., Kobayashi, K., Kobayashi, M., Hoshino, T., Horie, K. and Kimata, K. (1990). Occurrence in chick embryo vitreous humor of a type IX collagen proteoglycan with an extraordinarily large chondroitin sulfate chain and short alpha 1 polypeptide. J. Biol. Chem. 265, 6992-6999.

Yamamoto, Y. and Jeffery, W. R. (2000). Central role for the lens in cave fish eye degeneration. Science 289, 631-633.

Yang, Y., Drossopoulou, G., Chuang, P. T., Duprez, D., Marti, E., Bumcrot, D. Vargesson, N., Clarke, J., Niswander, L., McMahon, A. et al. (1997) Relationship between dose, distance and time in Sonic Hedgehog-mediated regulation of anteroposterior polarity in the chick limb. Development 124 4393-4404.

Zhang, H.-L., Guo, B., Yang, Z.-Q., Duan, C.-C., Geng, S., Wang, K., Yu, H.-F. and Yue, Z.-P. (2017). ATRA signaling regulates the expression of COL9A1 through BMP2-WNT4-RUNX1 pathway in antler chondrocytes. J. Exp. Zool. B Mol. Dev. Evol. 328, 575-586.

Zhao, S., Chen, Q., Hung, F. C. and Overbeek, P. A. (2002). BMP signaling is required for development of the ciliary body. Development 129, 4435-4442.

Zinn, K. M. (1970). Changes in corneal ultrastructure resulting from early lens removal in the developing chick embryo. Invest. Ophthalmol. 9, 165-182. 